\title{
RELAP5-3D three-dimensional analysis based on PHÉNIX dissymmetric transient test
}

\author{
Vincenzo Narcisi ${ }^{1}$ \\ DIAEE - Nuclear Section, "Sapienza" University of Rome \\ Corso Vittorio Emanuele II, 244, 00186, Rome, Italy \\ vincenzo.narcisi@uniroma1.it \\ Fabio Giannetti \\ DIAEE - Nuclear Section, "Sapienza" University of Rome \\ Corso Vittorio Emanuele II, 244, 00186, Rome, Italy \\ fabio.giannetti@uniroma1.it

\section{Andrea Subioli} \\ DIAEE - Nuclear Section, "Sapienza" University of Rome \\ Corso Vittorio Emanuele II, 244, 00186, Rome, Italy \\ sblndr92@gmail.com
}

\author{
Alessandro Del Nevo \\ Italian National Agency for New Technologies, Energy and Sustainable Economic \\ Development, C.R. ENEA Brasimone \\ Località Brasimone, 40032 Camugnano (Bologna) \\ alessandro.delnevo@enea.it
}

\section{Gianfranco Caruso}

DIAEE - Nuclear Section, "Sapienza" University of Rome Corso Vittorio Emanuele II, 244, 00186, Rome, Italy gianfranco.caruso@uniroma1.it

\begin{abstract}
Before the final shutdown of the PHÉNIX fast reactor, the CEA carried out a final set of experimental tests to gather data and additional knowledge on relevant Sodium Fast Reactors (SFR) operation and safety aspects. One of these experiments conducted was the dissymmetrical configuration test, which was
\end{abstract}

${ }^{1}$ Corresponding author. 
Journal of Nuclear Engineering and Radiation Science, Vol. 6, No. 1, 011301. DOI: 10.1115/1.4044847

selected as benchmark transient within the H2020 SESAME project. ENEA and Sapienza University of Rome are participating in the benchmark using the RELAP5-3D ${ }^{\odot}$ code. The thermal hydraulic analysis focuses on adequate core cooling prediction in accidental scenario. With the goal of investigating asymmetric thermal hydraulic behavior inside of the reactor pool, two different nodalization approaches have been applied for the RELAP5-3D ${ }^{\odot}$ model, which adopt the same geometrical scheme for the primary flow path, with the exception of the hot and cold pools and the core bypass. The first scheme has been developed using vertical parallel pipes with cross-junctions for the hot and cold pools and an equivalent pipe to reproduce the core bypass. The second model includes a multi-dimensional (MULTID) component which simulates the pools and provides a detailed nodalization of the core bypass. The present study aims at assessing whether the two modeling approaches are equally capable to predict the asymmetrical temperature evolution over the test, caused by the azimuthal asymmetry of the boundary conditions. Blind calculation results are presented and discussed. The paper will be a first step toward the RELAP5-3D ${ }^{\odot}$ code assessment against the experimental results collected as part of the PHÉNIX dissymmetric test.

\section{INTRODUCTION}

The PHÉNIX reactor [1] dissymmetrical configuration test has been selected as a benchmark transient within the Horizon 2020 - thermal-hydraulics Simulations and Experiments for the Safety Assessment of MEtal cooled reactor (H2020 SESAME) project [2] to demonstrate the capability of system thermal hydraulics codes (stand alone or in coupling configuration with Computational Fluid Dynamics (CFD) codes) to predict three-dimensional pool phenomena.

The main objectives of this activity are the validation of RELAP5-3D ${ }^{\odot}$ system code for the transient simulations of liquid metal-cooled fast reactors, the comparison of best-estimate thermal-hydraulic system code calculations with experimental data, 
and the identification of RELAP5-3D ${ }^{\odot}$ code (version 4.3.4) [3] limitations and sources of uncertainties. In achieving these objectives, the work described herein helps to improve the understanding of thermal-hydraulic phenomena observed in asymmetrical tests and to develop a reliable approach for the application of thermal-hydraulic system codes in the safety analysis of new generation fast reactor systems. This is because transients and thermal-hydraulic phenomena occurred in PHÉNIX are representative of those expected to characterize larger scale fast reactor systems. This implies that models and correlations affecting the code's capability to predict phenomena of interest can be assessed within a range of thermal-hydraulic parameters representative of candidate reactor designs.

In literature some examples were found on the applicability of RELAP5-3D ${ }^{\odot}$ (R53D) for the analysis of Sodium-cooled Fast Reactors (SFR). In 2006, R5-3D capabilities were evaluated for the application as the thermal hydraulic system code supporting the development of the Actinide Burner Test Reactor (ABTR) [4]. The assessment process highlighted adequate capabilities of the code for simulating SFRs, even if some improvements in the code's models were suggested. The main limits can be summarized in the lack of thermal stratification model for large tanks and the lack of axial conduction within the working fluid. Furthermore, this activity showed that minor changes on heat transfer coefficient correlations for liquid metals are required to improve the simulation of important thermal hydraulic phenomena [4].

The ability of RELAP5-3D ${ }^{\odot}$ to reproduce thermal stratification phenomena in large liquid metal pools was investigated in [5]. Two different pool modelling approaches were 
assessed, using a set of parallel vertical channels with cross junctions and a multidimensional component. The comparison of the simulation results with experimental data confirmed the suitability of R5-3D to reproduce thermal stratification in large tanks. In addition, a negligible effect of the axial conduction in the working fluid on the accuracy of the solution was observed, mainly due to the small magnitude of the thermal gradient.

Thermal conduction can produce relevant effect within the fuel assemblies, where a large temperature difference occurs along the axial direction. As presented in [6], axial conduction in liquid metal systems is an important factor when the Peclet number $(\mathrm{Pe})$ is less than 100 , typically in natural circulation condition. In the experimental campaign considered here, the primary pumps operated over the whole test and the assumption to neglect the axial thermal conduction is justified by the high value of Pe.

As mentioned above, the heat transfer coefficient correlations implemented in R5-3D for liquid metal present some limits. At this regard, corrective factors have been implemented in the PHÉNIX modelling.

On this basis, the paper discusses the development and the validation of two thermal-hydraulic modeling approaches of the PHÉNIX primary and secondary systems using the system code RELAP5-3D ${ }^{\odot}$.

\section{PHÉNIX REACTOR}

PHÉNIX is a $563 \mathrm{MW}_{\text {th }}$ sodium-cooled pool-type fast reactor, with an electric output of approximately $250 \mathrm{MW}_{\mathrm{el}}$, located at the Marcoule nuclear site, near Orange, France. Its construction began in November 1968 and the plant was first connected to 
the French national electricity grid in December 1973. From 1993 to the end of the electricity production in 2009, the reactor has been operated at a reduced power of 350 $\mathrm{MW}_{\text {th }}\left(140 \mathrm{MW}_{\mathrm{el}}\right)[7]$.

Figure 1 shows the reactor block [8], which is a suspended type: all the vessels are supported by the upper cover slab, which is provided with flanges for the replacement/maintenance of the reactor components. The main vessel, which ensures biological protection, has a diameter of $11.8 \mathrm{~m}$ and it contains about 800 tons of primary sodium. The main vessel is attached to the upper slab by means of 21 suspension hangers and it is closed by means of a flat roof, featuring penetrations for the components. Any possible sodium leak is contained by the double-enveloped vessel, which is welded to the upper part of the main vessel. The roof and the double envelope vessel are thermally insulated. The third vessel represents the primary containment; it is welded to the underside of the slab and it is attached to the reactor pit. The role of the third vessel is to contain radioactive products in case of severe accidents [8]. Below the core, the strongback, together with the conical shell, has the function of supporting the above structures and redirecting about $10 \%$ of the operating flow to the Vessel Cooling System (VCS). Above the strongback, the diagrid connects the Primary Pumps (PP) to the core, suppling the primary coolant to each Sub-Assembly (SA). The reactor core consists of an array of hexagonal assemblies, represented in Fig. 2. Each assembly has overall length of $4.3 \mathrm{~m}$; the fuel is mixed uranium-plutonium oxide [9][10]. The central fissile zone is divided into two regions having different enrichment, and it is surrounded by annular fertile zones, Axial Reflector Assemblies (ARA), and lateral neutron shielding 
rods. The reactor control is ensured by means of 6 control rods and 1 safety rod, that represent the complementary shutdown system (Système d'Arrêt Complémentaire, SAC).

The core is located inside of the primary vessel (see Fig. 1), which separates the hot from the cold pool in the main vessel. The hot sodium, exiting the core, flows into the hot pool and subsequently moves through the inlet to the six intermediate, straight tube heat exchangers (see Fig. 1 and Fig. 3), marked as IHX and DOTE in Fig. 3. The primary coolant flows downward through the shell side of the IHX and it is discharged into the cold pool. Three vertical-axis primary pumps ensure the primary coolant circulation, drawing the sodium from the cold pool and pumping it into the diagrid through three connector pipes. The six IHX, in groups of two, represent the interface between the primary system and three secondary loops. Each secondary loop is equipped with a mechanical pump located inside the expansion tank, a buffer tank and the auxiliary systems, which ensure the sodium storage, filling, and purification. Each secondary loop feeds secondary sodium to a steam generator that supplies the thermal power to a tertiary circuit operating with water as a fluid in a conventional Rankine cycle.

From 1993 until the final shutdown of the reactor in 2009, the secondary loop No. 2 was not operating and the two corresponding heat exchangers (called DOTE in Fig. 3) were plugged. The Primary Pump No. 2 (PP2) was instead operating normally.

\section{THE DISSYMMETRICAL TEST}


In 2009 two dissymmetrical tests were performed, one on each of the operating secondary loops (LOOP 1 and LOOP 3). The results of these tests support liquid metal reactor plant design. As the results of the tests were similar, thus proving test repeatability, only the test on LOOP 1 was considered in this study.

The test taken into consideration in this work started from nominal steady state conditions, i.e. full power and flow rates, followed by a sequence of events summarized in Table 1. The initiating event was the trip of the secondary coolant pump (on LOOP 1), with the speed reduced from 700 to $100 \mathrm{rpm}$ in about $13 \mathrm{~s}$. This resulted in azimuthal and axial asymmetry in the cold pool, with the reduction in cooling resulting in a rapid temperature increase in the cold pool at the outlet of IHX 1. After 5 seconds from the beginning of the test, automatic shutdown occurred (with the control rods inserted at a velocity of $1.4 \mathrm{~mm} / \mathrm{s}$ for $45 \mathrm{~s}$ ) and the speed of the secondary pump in LOOP 3 was reduced from 700 to $110 \mathrm{rpm}$ in about $60 \mathrm{~s}$, after the turbine trip signal.

At $48 \mathrm{~s}$ the scram command was operated and the test terminated after 1800 seconds.

\section{PHÉNIX MODEL}

RELAP5-3D ${ }^{\odot}$ was developed by Idaho National Laboratory (INL). It is a versatile code that, in addition to predicting the behavior of a reactor coolant system during a transient, can be used for the simulation of a wide variety of hydraulic and thermal transients in both nuclear and non-nuclear systems involving mixtures of vapor, liquid, non-condensable gases, and nonvolatile solute. R5-3D has fully integrated, multi- 
dimensional thermal hydraulic and reactor kinetics modeling capability. This allows the application of the code to the full range of postulated reactor accidents. It has implemented all features and models previously available in the ATHENA code (INL): several working fluids (e.g. helium, hydrogen, lead, lead-bismuth, lithium, lithium-lead, molten salts, sodium, sodium-potassium, etc.) can be modeled, and a simplified magneto-hydrodynamic model is also included in the code [11][12].

The R5-3D mono-dimensional model (1D MODEL) of the PHÉNIX reactor was presented in [13], and nodalization is shown in Fig. 4 and Fig. 5. The three-dimensional model (3D MODEL) adopts the same nodalization scheme, except for the pools, the diagrid and the core bypass, which are modeled as MULTI-Dimensional (MULTID) components, as discussed later. The modeling adopted in the 1D model for the core, hot and cold pools, IHXs, pumps, diagrid, strongback and vessel cooling system, is described as follows.

CORE

The reactor core is divided into three main regions (see Fig. 2):

1) the inner and outer core (corresponding to the innermost 7 rings of assemblies): each is represented with 127 parallel pipes (one pipe for each assembly);

2) the blanket zone (rings greater than 7): it is modeled with 36 equivalent pipes, simulating the radial blanket, the Axial Reflector Assemblies (ARA) and the storage assemblies (for the cooling of spent fuel) grouped separately, according to their azimuthal configuration; 
3) the shielding zone: it is modelled with 24 equivalent pipes which include the neutronic shielding and boron carbide shielding elements.

The model of each sub-assembly in the core regions is rather detailed to represent the relevant geometric characteristics.

The bypass zone is modelled with 2 equivalent pipes (305 and 303 in Fig. 4) and the heat losses through the SA hexagonal wrap are simulated with 3722 heat structures, reproducing the heat conduction through the wrap thickness, assuming the thermophysical properties of the structural materials provided by the French Alternative Energies and Atomic Energy Commission (CEA) [14]. The fuel assembly orifices are set up based on the mass flow rate data and overall dynamic pressure drops in the nominal steady state [9].

HOT and COLD POOL

The hot pool is divided into 7 components to respect the reactor geometry and to represent the relevant thermohydraulic zones. The pipes 312, 314, 316 (Fig. 4) model the annular region just upstream of the IHXs; channels 306, 308, 310 which model the volumes above the core and the branch 941 represents the upper region of the hot pool, containing the free level of primary coolant. Each component is connected with multiple cross junctions to reproduce the mixing of the sodium. The cold pool follows the same nodalization scheme of the annular region of the hot pool, as shown in Fig. 4. INTERMEDIATE HEAT EXCHANGERS (IHXS)

The IHXs primary side is modeled separately with PIPE components connected upstream and downstream with the correspondent region of hot pool and cold pool. 
The IHXs secondary sides are modeled separately with pipe components from an inlet and outlet collectors (dummy) and fed with imposed boundary conditions. Fig. 5 shows the representative nodalization scheme of the heat exchangers. Primary and secondary sides of DOTE components (Fig. 3) are modeled and disabled closing the connections between the IHXs No. 2 and the hot pool, to prevent the primary coolant to flow through them.

\section{PRIMARY PUMPS}

The pumps are simulated with a vertical pipe in which coolant flows upward, reproducing the annular inlet to the component, connected with the corresponding region of the cold pool, with the PUMP component and with the vertical pipe which contains the primary coolant flowing downward to the diagrid (component 302 in Fig.

4). The nodalization scheme is showed in Fig. 5. The homologous curves of the PUMP components are set-up using PHÉNIX reference data [14].

DIAGRID, STRONGBACK and VESSEL COOLING SYSTEM

The diagrid is modelled with branch component (302 in Fig. 4) connected below with the strongback and above with the SAs and the bypass region. The nodalization scheme of the vessel cooling system and the strongback is shown in Fig. 5; it consists of the pipe 945 , connected upstream with the diagrid, on the top with the gas plenum (972), and downstream with the corresponding regions of cold pool.

The components, described above, are also adopted in the 3D MODEL, except for the pools, the diagrid and the core bypass, which are modelled with a multidimensional component (see Fig. 6 and Fig. 7). This component is composed of 35 axial 
lengths, 6 radial rings and 12 azimuthal sectors. The first three radii are chosen to divide the core region in three zones (fuel zone, blanket-reflector zone, and natural circulation zone), and the fourth, fifth and sixth radii are chosen to uniformly divide the cold pool (radius 4 measures up to the axle of the IHXs and the PPs, radius 5 is chosen to have the azimuthal sectors with the same area of radius 4 , and radius 6 corresponds to the primary vessel inner diameter). The number selection of azimuthal meshes is based on the PPs and IHXs geometrical positions (see Fig. 6). The axial mesh lengths of the cold and hot pool regions and of the other components (reactor zone, skirt and PPs pipes, IHX, and VCS) are consistent with the vertical sliced approach (see Fig. 7). Each 1D component is placed according with the $3 \mathrm{D}$ geometrical specifications and the relevant elevations are preserved. In order to represent the actual amount of fluid contained in each volume of MULTID component, the porosity factor and the junction factor are used.

The pressure drop in the rod bundle is evaluated using the Cheng and Todreas correlation for laminar, turbulent and transition flows [15]. Specifically, the standards R5-3D wall friction correlations were modified as to reproduce the Cheng and Todreas formulation, simulating a wire-wrapped rod bundle by form loss coefficient with a Re dependence, as described in [4][16].

For the evaluation of the Heat Transfer Coefficient (HTC) for liquid metals, RELAP5-3D ${ }^{\odot}$ provides two different correlations depending on the geometry (nonbundle or bundle) [12], for all convective wall heat transfer (turbulent forced, laminar forced, and natural). For non-bundles the Seban-Shimazaki correlation [17] is used: 


$$
N u=5.0+0.025 P e^{0.8}
$$

where Nu is the Nusselt number and Pe is the Peclet number. When Pe goes to zero, Nu tends to 5 in order to reproduce the HTC in natural circulation conditions. For the HTC evaluation in bundle geometry, the Westinghouse correlation is integrated in RELAP5-3D ${ }^{\odot}[12]$ and it is used to calculate the heat transfer coefficient inside the SAs:

$$
N u=4.0+0.33\left(\frac{p}{D}\right)^{3.8}\left(\frac{P e}{100}\right)^{0.86}+0.16\left(\frac{p}{D}\right)^{5}
$$

where $p$ is the rod pitch and $D$ the rod diameter. The correlation has been developed for a range of Pe from 10 to 5000 and of pitch to diameter ratio $(p / D)$ from 1.1 to 1.4 , even if this correlation seems to underestimate Nu number for $p / D$ higher than 1.3 [4]. The IHXs are characterized by a $p / D$ equal to 1.43 ; for this reason, the Graber \& Rieger correlation [18], not implemented in the current version of R5-3D, has been selected to evaluate the HTC in the IHXs primary side:

$$
N u=0.25+6.2 \frac{p}{D}+\left(-0.007+0.032 \frac{p}{D}\right) P e^{\left(0.8-0.024 \frac{p}{D}\right)}
$$

developed for $1.2<p / D<2.0$. In the operational range of temperature and pitchto-diameter ratio, the two correlations have a similar gradient of Nu versus Pe; therefore, a constant HTC multiplication factor equal to 1.4, calculated as the ratio of Graber \& Rieger and Westinghouse correlations, has been applied in the IHX primary side model.

\section{RESULTS}


In order to obtain the initial conditions for the transient test, the full power operation is first analyzed. Table 2 summarizes the nominal (full power operation) boundary conditions and Table 3 the comparison of 1D and 3D models results of the nominal steady state calculations. Based on the same boundary conditions (in Table 2), the two models provide very similar results, even if some discrepancies are observed in the temperature profile within the cold pool, and with the 3D model requiring a computational time three times longer than the $1 \mathrm{D}$ model. In regard to the temperature profile within the cold pool, the three-dimensional nodalization of the pool offers a more detailed resolution of the temperature in the large volume, as shown in Fig. 8 (a) and Fig. 9 (a), which compare the initial temperatures in a slice of the pool in the two models. In this figures, the $x$-axis represents the $\theta$-coordinate, showing the axial temperature distribution calculated in the control volumes between Radius 4 (R4) and Radius 5 (R5) on the r-coordinate (see Fig. 6) The pool nodalization using three pipes and several cross junctions has been obtained in order to reproduce buoyancy effects inside the large volume, but this modelling approach implies that the pump inlet and the outlet of the corresponding IHXs are connected with the same pipe. This approach is not able to provide a temperature profile in the vertical direction around the shell of the pumps and IHXs (see Fig. 8 (a)). The MULTID component allows a more detailed nodalization, as shown in Fig. 9 (a), able to provide results with a higher resolution; Figure 9 (a) highlights that the hot sodium, inside the cold pool, is drawn into the pump, providing a significant vertical stratification around this component and causing a higher temperature at the core inlet (about 1 degree), shown in Table 3. 
Starting from the nominal (full power) steady state conditions, the capability of the two approaches to reproduce the evolution of the temperature inside the large pools is analyzed as follows.

The dissymmetric test is reproduced following the sequence of events summarized in Table 1. At the beginning of the test, the secondary mass flow rate within LOOP 1 decreases, causing the fast reduction of the thermal power removed by the IHX$1 \mathrm{~A}$ and IHX-1B. Figure 10 compares the thermal power removed by LOOP $1(\mathrm{IHX}-1 \mathrm{~A}+$ IHX-1B) and LOOP $3(\mathrm{IHX}-3 \mathrm{~A}+\mathrm{IHX}-3 \mathrm{~B})$ in the first $200 \mathrm{~s}$ of the transient. The delay in power reduction by LOOP 3 , due to the delay time of LOOP 3 trip, is also highlighted in Fig. 11. During the first $30 \mathrm{~s}$, the thermal power removed by LOOP 3 increases up to $85 \%$ of the total power; at this time, the power removed by LOOP 1 reaches and maintains the value of about $20 \mathrm{MW}$, while the power removed by LOOP 3 continues to decrease, reaching the same value of LOOP 1 at about $70 \mathrm{~s}$. The timing of the events predicted by the two modelling approaches is the same, with no appreciable differences. Figure 12 shows the IHX outlet temperatures. At the IHX-1A and IHX-1B outlet (represented by IHX1 in the figure), the primary coolant temperature quickly increases to a peak of 773 $\mathrm{K}$, with the same trend in the two models. After a delay of $30 \mathrm{~s}$, also the outlet temperature of IHX-3A and 3B increases, reaching a maximum value which is slightly different between the two models ( $770 \mathrm{~K}$ for the $1 \mathrm{D}$ model and $762 \mathrm{~K}$ for the 3D model). The effect of the delayed trip of LOOP 3 is an asymmetric distribution of the temperature inside of the cold pool, as shown in Fig. 8 and Fig. 9. In the first seconds of the transient, the decrease in thermal power removed by LOOP 1 causes a small 
increase in temperature at the IHX1 exit (see "X" in Fig. 8 and Fig. 9). Subsequently, after $30 \mathrm{~s}$, the hot fluid moves to the upper part of the cold pool, in the volumes around IHX1, and the cooler fluid moves downward (see Fig. 8 (b) and Fig. 9(b)). Between 30 and 60 s, the same effect occurs at the outlet section of IHX3 (see "O" in Fig. 8 and Fig. 9). At this time, the upper part of the cold pool is completely heated by the hot fluid exiting from $\mathrm{IHX1}$; for this reason, the hot sodium exits from IHX3 and moves downward, reaching the Primary Pump 3 (PP3) inlet section (see " $\mathrm{Y}$ " in Fig. 8 (c) and Fig. 9(c)). This effect results in a peak temperature of about $680 \mathrm{~K}$ at the PP3 inlet, shown in Fig. 13, which highlights a slight delay in reaching the peak temperature when adopting the monodimensional scheme of the pool. This is probably due to a better estimation of the buoyancy effects allowed by the three-dimensional momentum equations implemented in the MULTID component. After the first phase of the transient, the two models provide similar trends for the temperature at the outlet of the IHXs, however the 3D model predicting temperatures three degrees lower than the 1D MODEL. The MULTID approaches provides a more detailed temperature distribution inside the pool, highlighting not only a vertical stratification of the temperature (also predicted by the 1D MODEL), but also predicting different temperatures in the different azimuthal sectors of the pool. At the beginning of the test, the 1D MODEL predicts a thermal stratification at the same level in each azimuthal sector (about $3 \mathrm{~m}$ above the bottom of the pool, see Fig. 8 (a)); at the same time, Fig. 9 (a) shows that the 3D MODEL provides a more detailed solution, in which the thermal stratification level moves from $3 \mathrm{~m}$ (within the sector including the active IHXs) to $1.5 \mathrm{~m}$ (within the section including the PPs). This 
leads to a discrepancy on the evaluation of the sodium temperature at the primary pumps inlet, under-predicted by the 1D MODEL of about 1 degree at the beginning of the transient test and of about 3 degrees over the whole dissymmetric test.

The lower temperature at the primary pumps inlet causes a higher sodium density and, consequently, a slightly higher mass flow rate when adopting the 3D MODEL (see Fig. 14). The maximum discrepancy is observed at $180 \mathrm{~s}$, when each PP of the 3D MODEL draws a primary mass flow rate higher of about $5 \mathrm{~kg} / \mathrm{s}$ in comparison with 1D MODEL.

Figure 15 shows the core inlet and outlet temperatures, comparing the $1 \mathrm{D}$ and $3 \mathrm{D}$ results. The prediction of a smaller primary mass flow rate leads to an overprediction of the core temperature increase by the 1D MODEL (the discrepancy in terms of temperature increase is 3 degrees at the beginning and $0.6 \mathrm{~K}$ at the end of the test). From 5 to $48 \mathrm{~s}$, the temperature difference across the core decreases, due to the automatic shutdown. The 3D MODEL predicts a faster decrease of the outlet temperature, due to the higher mass flow rate through the core. Then, the inlet temperature increases, following the trend shown in Fig. 13, and the temperature difference continues to decrease after reactor scram. The sodium temperature decreases up to the end of the test. The inlet temperature of the IHXs is depicted in Fig. 16. It follows the same trend of the core outlet temperature; the 1D MODEL predicts a slight difference between IHX1 and IHX3 during the first $200 \mathrm{~s}$, which is not reproduced by the MULTID approach.

\section{CONCLUSIONS}


The dissymmetric test, carried out in the PHÉNIX reactor, offers useful experimental data for the validation of thermal-hydraulic system codes, especially regarding their capability to predict thermal-hydraulic asymmetries in liquid metal pool reactors.

The mono-dimensional and the three-dimensional models are carried out using the RELAP5-3D ${ }^{\odot}$ code. Both models reproduce steady state conditions in good agreement with the benchmark specifications. Small differences in prediction exist at the inlet and outlet temperature of the core, due to a different prediction of the temperature distribution inside the pool. In addition, the nodalization of the pool strongly influences the main thermal-hydraulic parameters during the transient test; the simplified 1D model allows faster calculations, but it is not able to provide a detailed analysis of the main quantities (such as sodium temperature and buoyancy) in the large pools. A comparison with the experimental data, from the experimental campaign conducted at PHÉNIX reactor [11], will be used to evaluate whether the better predictive capability of the MULTID model is enough to justify its adoption despite the longer computational time required for the calculations.

\section{ACKNOWLEDGMENT}

The authors would like to thank CEA and, in particular, A. Gerschenfeld for providing data for the realization of the validation benchmark.

\section{FUNDING}


Journal of Nuclear Engineering and Radiation Science, Vol. 6, No. 1, 011301. DOI: 10.1115/1.4044847

The SESAME project has received funding from the Euratom research and training programme 2014-2018 under grant agreement No 654935. 


\section{NOMENCLATURE}

\begin{tabular}{|c|c|}
\hline ABTR & Actinide Burner Test Reactor \\
\hline ARA & Axial Reflector Assembly \\
\hline CEA & French Alternative Energies and Atomic Energy Commission \\
\hline CFD & Computational Fluid Dynamics \\
\hline CPU & Central Processing Unit \\
\hline$D$ & Diameter, m \\
\hline DOTE & $\begin{array}{l}\text { Dispositif d'Obturation des Traverses d'Echangeurs (Exchangers plugging } \\
\text { system) }\end{array}$ \\
\hline ENEA & $\begin{array}{l}\text { Agenzia nazionale per le nuove tecnologie, l'energia e lo sviluppo } \\
\text { economico sostenibile }\end{array}$ \\
\hline $\mathrm{H} 2020$ & Horizon 2020 \\
\hline HTC & Heat Transfer Coefficient \\
\hline $\mathrm{IHX}$ & Intermediate Heat eXchanger \\
\hline INL & Idaho National Laboratory \\
\hline MF & Mass Flow rate, $\mathrm{kg} / \mathrm{s}$ \\
\hline MULTID & Multidimensional component \\
\hline $\mathrm{Nu}$ & Nusselt number \\
\hline $\mathrm{Pe}$ & Peclet number \\
\hline
\end{tabular}




$\begin{array}{ll}p & \text { Pitch, } \mathrm{m} \\ \text { PP } & \text { Primary Pump } \\ \text { Pth } & \text { Thermal Power, W } \\ \text { R } & \text { Radius } \\ \text { RELAP } & \text { Reactor Excursion and Leak Analysis Program } \\ \text { SA } & \text { Sub-assembly } \\ \text { SAC } & \text { Complementary shutdown system } \\ \text { SESAME } & \text { Thermal-hydraulics Simulations and Experiments for the Safety } \\ & \\ \text { VCS } & \text { Assessment of Metal cooled reactor } \\ & \\ & \text { Sodium-cooled Fast Reactor } \\ & \end{array}$




\section{REFERENCES}

[1] Sauvage, J.F., 2009. Phénix: 35 years of history: the heart of a reactor. CEA/Valrhô Edition, Bagnols-sur-Cèze, France.

[2] SESAME Project, Thermal-hydraulics Simulations and Experiments for the Safety Assessment of Metal cooled reactor, April 2015. EURATOM H2020, Grant Agreement N. 654935.

[3] INL, The RELAP5-3D@ Code Development Team, RELAP5-3D ${ }^{\odot}$ Code Manual Volume I: Code Structure, System Models and Solution Methods, INL/MIS-1536723, Revision 4.3, October 2015

[4] Davis, C.B., 2006. Applicability of RELAP5-3D for Thermal-Hydraulic Analyses of a Sodium-Cooled Actinide Burner Test Reactor, INL/EXT-06-11518. Free download from: https://inldigitallibrary.inl.gov/sites/sti/sti/3374827.pdf.

[5] Narcisi, V., Giannetti, F. and Caruso, G., 2019, Investigation on RELAP5-3D ${ }^{\odot}$ capability to predict thermal stratification in liquid metal pool-type system and comparison with experimental data, Nuclear Engineering and Design, Vol. 352, 110152, https://doi.org/10.1016/j.nucengdes.2019.110152.

[6] Kays,W.M. and Crawford, M.E., 1980. Convective Heat and Mass Transfer, Second Edition, McGraw-Hill Book Company, New York, NY, USA, 480 pages.

[7] Vasile, A., 2011. PHÉNIX final tests. Proceedings of the $11^{\text {th }}$ International Congress on Advances in Nuclear Power Plants (ICAPP-11), Nice, France, May 26, Paper \#11298.

[8] IAEA-TECDOC-1703, 2013. Benchmark analyses on the natural circulation test performed during the PHÉNIX end-of-life experiments. 186 pages. Free download from: https://wwwpub.iaea.org/MTCD/Publications/PDF/TE_1703_web.pdf.

[9] IAEA-TECDOC-1742, 2014. Benchmark analyses on the control rod withdrawal tests performed during the PHÉNIX end-of-life experiments. 262 pages. Free download form: https://www-pub.iaea.org/MTCD/Publications/PDF/TE1742_web.pdf.

[10] Varaine, F., 2009. IAEA CRP on PHÉNIX end of life tests: Control rod withdrawal, Technical Report CEA/DEN/CAD/DER/SPRC/LEDC. 
[11] INL, The RELAP5-3D@ Code Development Team, RELAP5-3D ${ }^{\odot}$ Code Manual Volume II: User's Guide and Input Requirements, INL/MIS-15-36723, Revision 4.3, October 2015

[12] INL, The RELAP5-3DC Code Development Team, RELAP5-3DC Code Manual Volume IV: Models and Correlations, INL/MIS-15-36723, Revision 4.3, October 2015

[13] Giannetti, F., Narcisi, V., Subioli, A. and Del Nevo, A., 2018. Phénix transient analysis for the assessment of RELAP5-3D based on dissymmetric test benchmark, Proceedings of the $26^{\text {th }}$ International Conference on Nuclear Engineering (ICONE-26), London, England, July 22-26, Paper \#82419. DOI: 10.1115/ICONE26-82419

[14] Grosjean, B. and Li, S., 2016. PHENIX dissymmetric test description, Deliverable D4.1, H2020 SESAME project, 39 pages.

[15] Cheng, S.K. and Todreas, N.E., 1986. Hydrodynamic models and correlations for bare and wire-wrapped hexagonal rod bundles - Bundle friction factors, subchannel friction factors and mixing parameters, Nuclear Engineering and Design, Vol. 92, No. 2, pp 227-251. https://doi.org/10.1016/00295493(86)90249-9

[16] Del Nevo, A. and Martelli, E., 2016. Validation of a Three-Dimensional Model of EBR-II and Assessment of RELAP5-3D Based on SHRT-17 Test, Nuclear Technology, Vol. 193, No. 1, pp 1-14 https://doi.org/10.13182/NT14-152

[17] Seban, R.A. and Shimazaki, T.T., 1950. Heat transfer to a fluid turbulently in a smooth pipe with walls at constant temperature, Transaction of the American Society of Mechanical Engineers, Vol. 73.

[18] Pfrang, W. and Sruwe, D., 2007. Assessment of Correlations for Heat Transfer to the Coolant for Heavy Liquid Metal Cooled Core Design, Forschungszentrum Karlsruhe $\mathrm{GmbH}$, Karlsruhe FZKA 7352. Free download from: http://citeseerx.ist.psu.edu/viewdoc/download?doi=10.1.1.499.6021\&rep=rep1 \&type $=p d f$ 


\section{Figure Captions List}

Fig. 1 Scheme of the PHÉNIX reactor block [8]

Fig. 2 Top view of the core [10]

Fig. 3 Top view of the reactor [8]

Fig. $4 \quad$ Core and pools nodalization scheme: 1D MODEL

Fig. 5 Pumps, IHX and VCS nodalization scheme

Fig. 6 Overview of radial and azimuthal meshes of MULTID component

Fig. 7 Scheme of MULTID component

Fig. $8 \quad$ Primary system temperature: 1D MODEL

Fig. 9 Primary system temperature: 3D MODEL

Fig. $10 \quad$ Power removed by IHXs

Fig. 11 Power \% removed by IHXs

Fig. 12 IHXs outlet coolant temperature

Fig. 13 PPs inlet coolant temperature

Fig. $14 \quad$ PPs mass flow rate

Fig. $15 \quad$ Core inlet and outlet temperature

Fig. $16 \quad$ IHXs inlet coolant temperature 
Journal of Nuclear Engineering and Radiation Science, Vol. 6, No. 1, 011301. DOI: 10.1115/1.4044847

\section{Table Caption List}

Table 1 Dissymmetrical test main events sequence

Table $2 \quad$ Nominal (full power operation) boundary conditions

Table 3 Comparison of 1D and 3D models results and CPU times of the nominal steady state calculations 


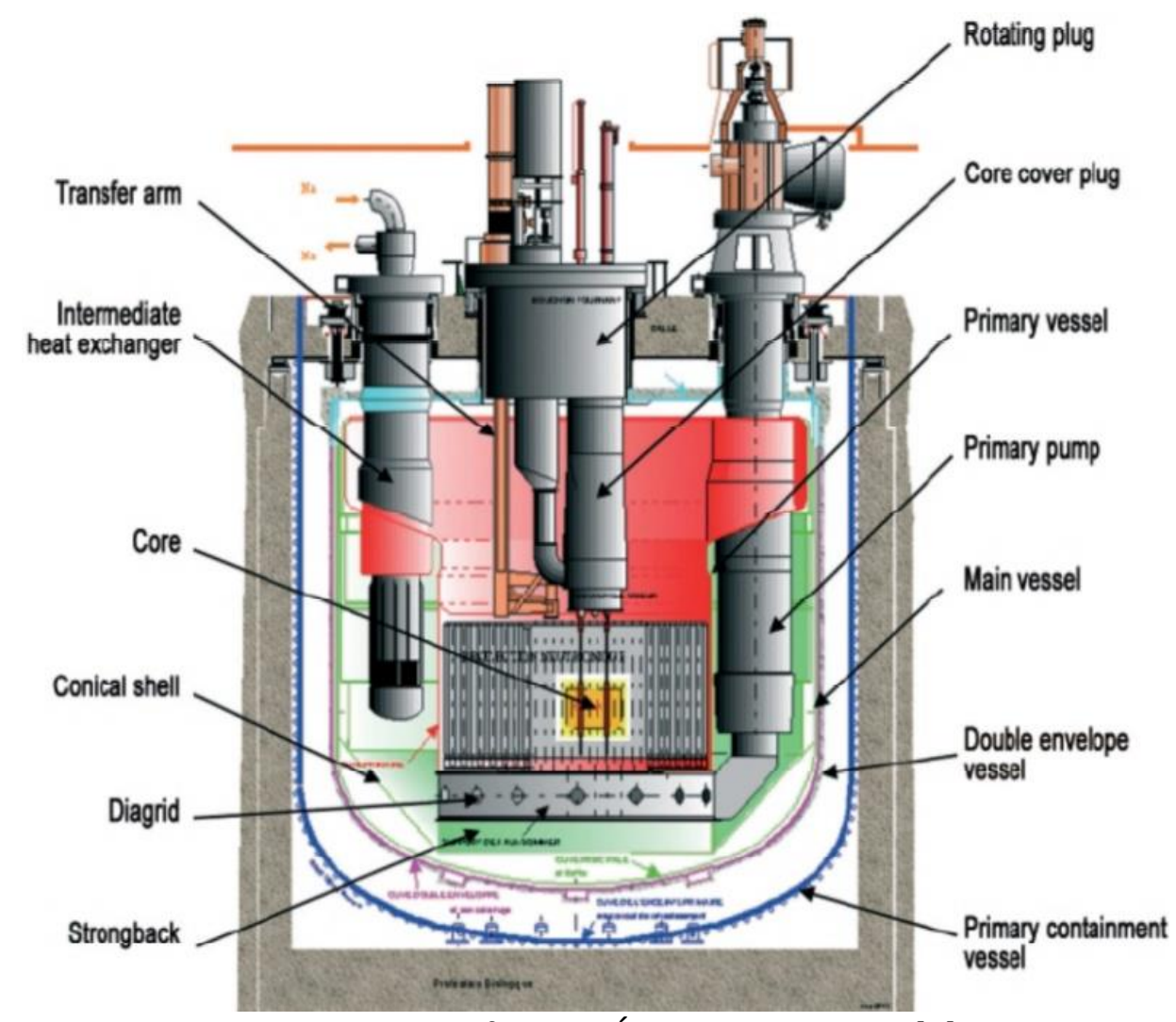

Fig. 1 Scheme of the PHÉNIX reactor block [8] 


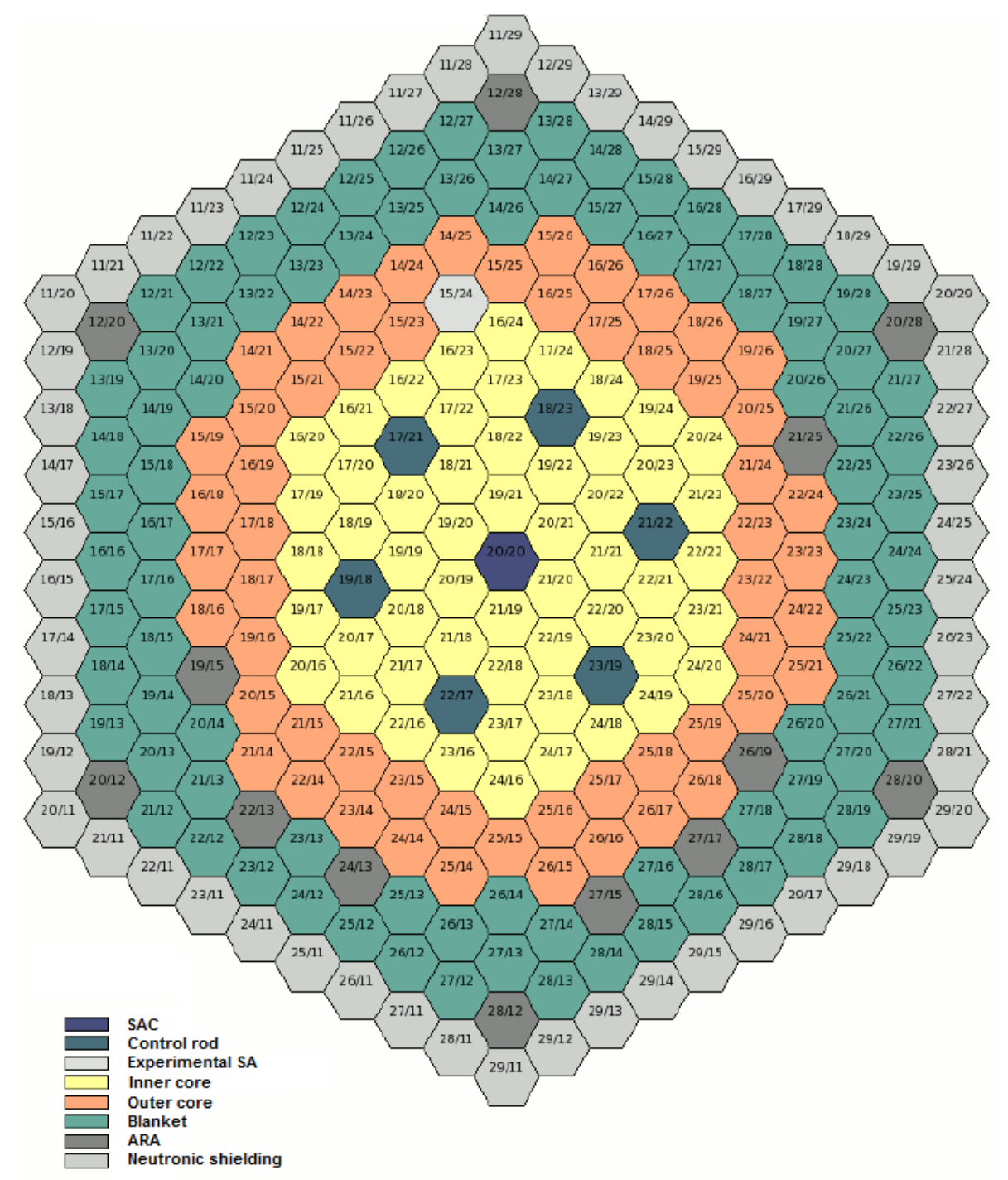

Fig. 2 Top view of the core [10] 


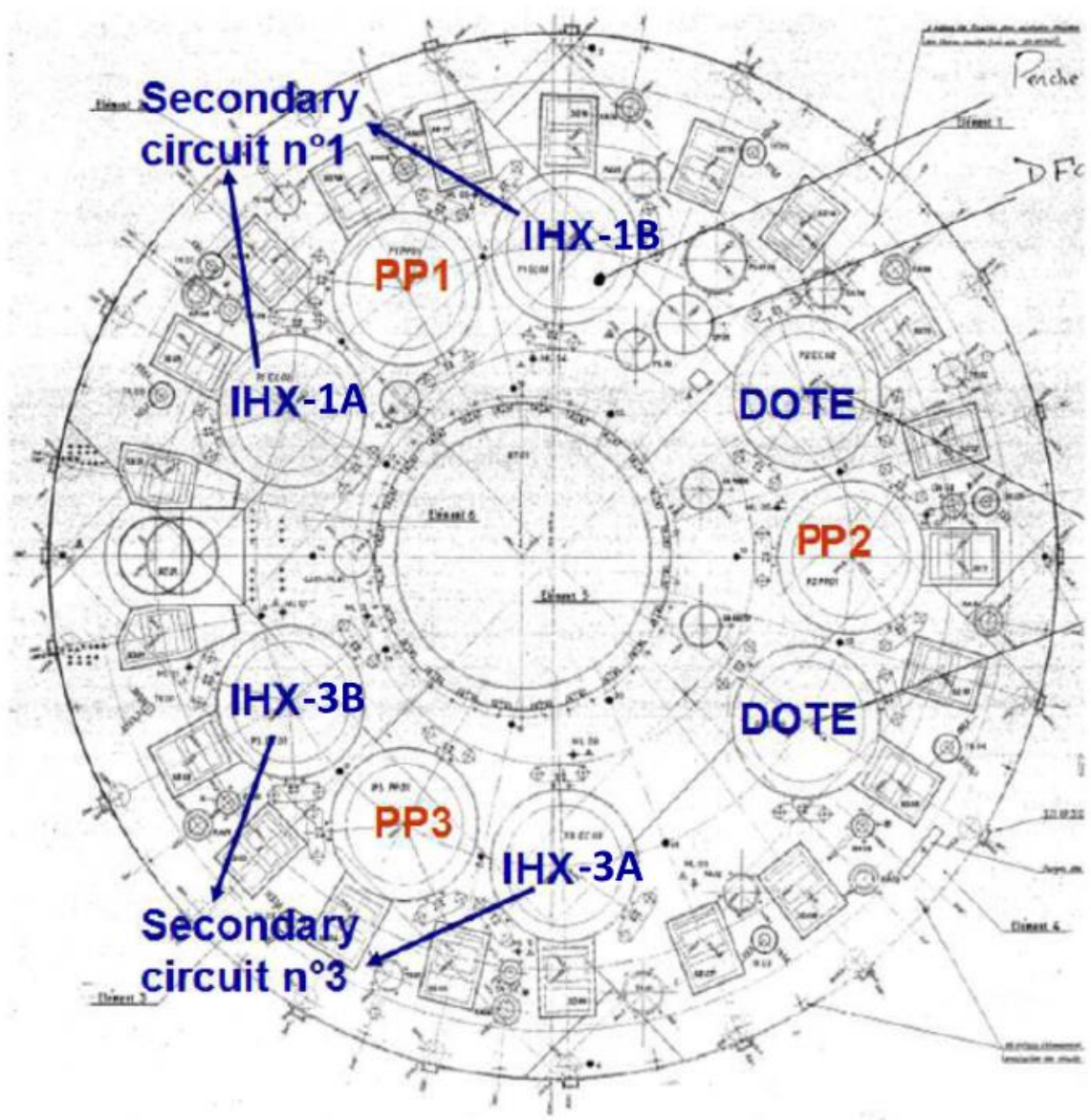

Fig. 3 Top view of the reactor [8] 


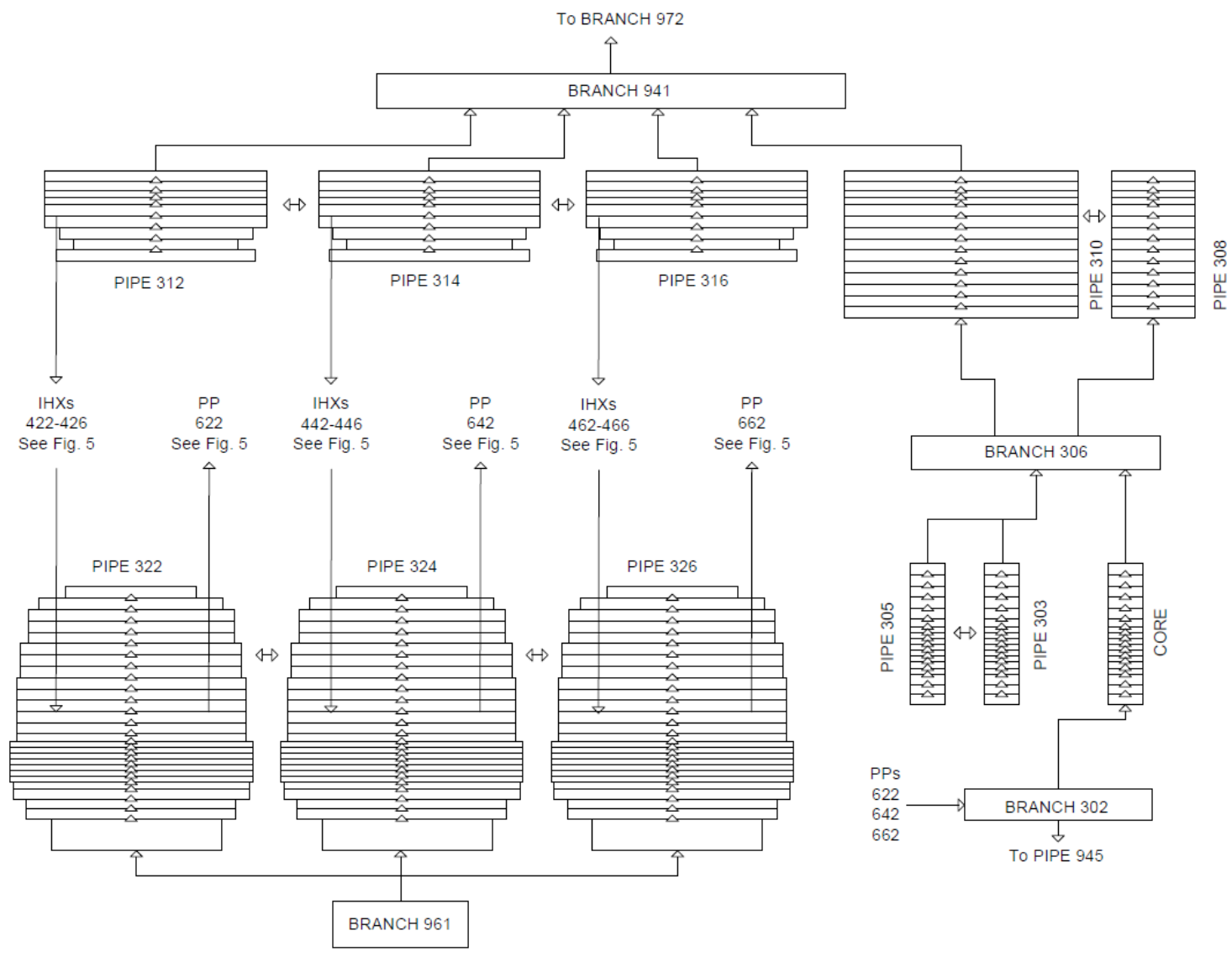

Fig. 4 Core and pools nodalization scheme: 1D MODEL 


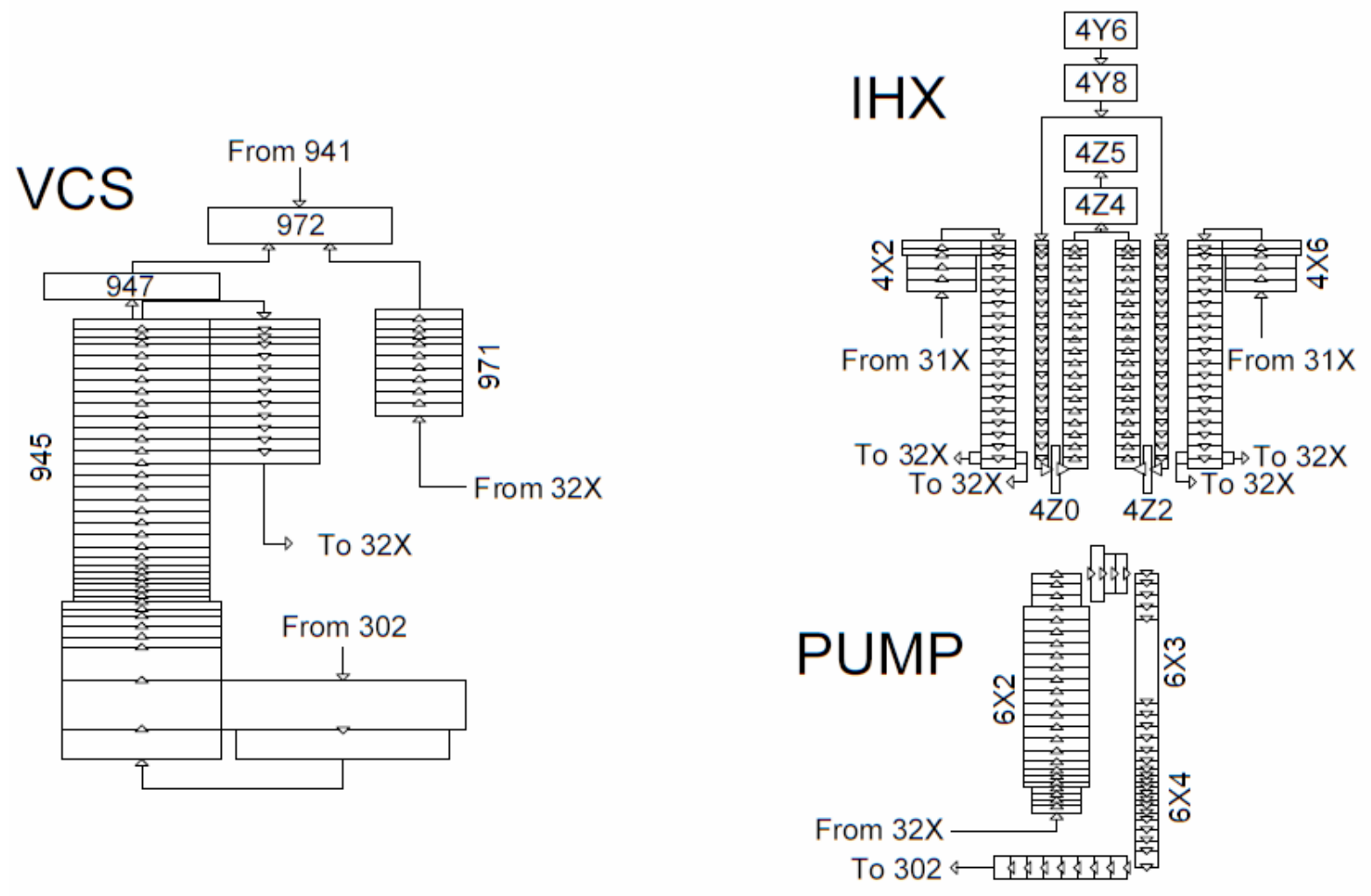

Fig. 5 Pumps, IHX and VCS nodalization scheme 


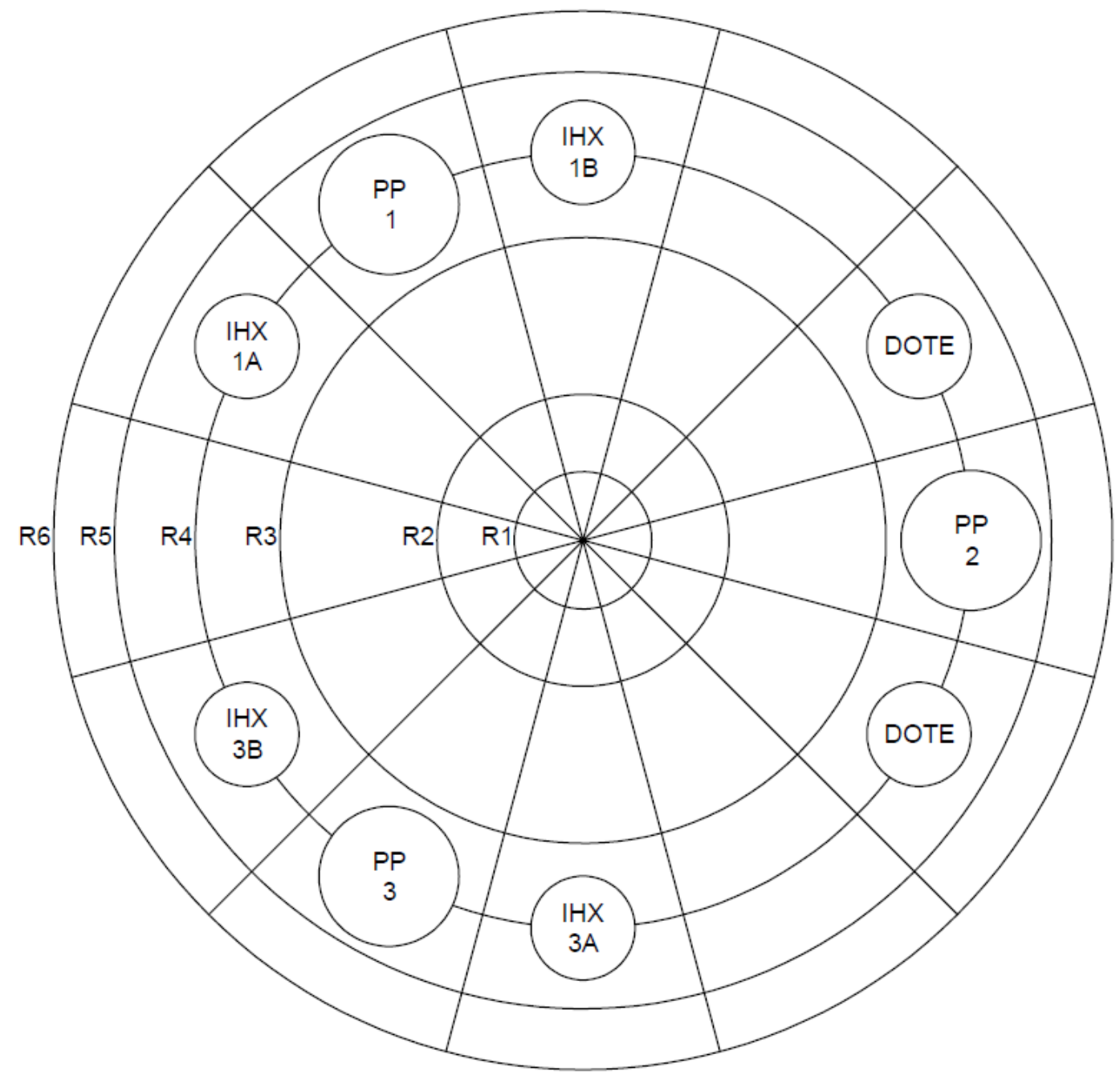

Fig. 6 Overview of radial and azimuthal meshes of MULTID component 


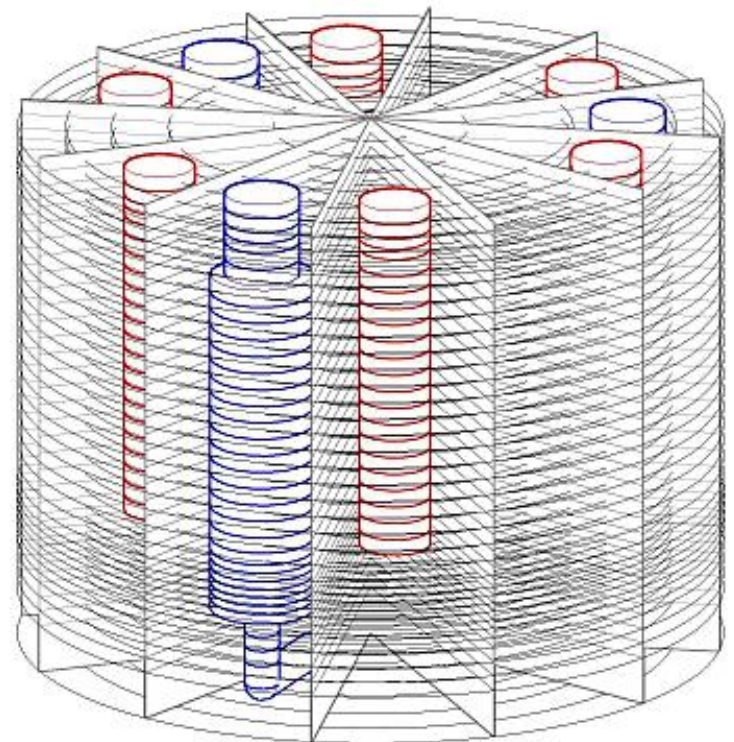

Fig. 7 Scheme of MULTID component 
Time 0 s

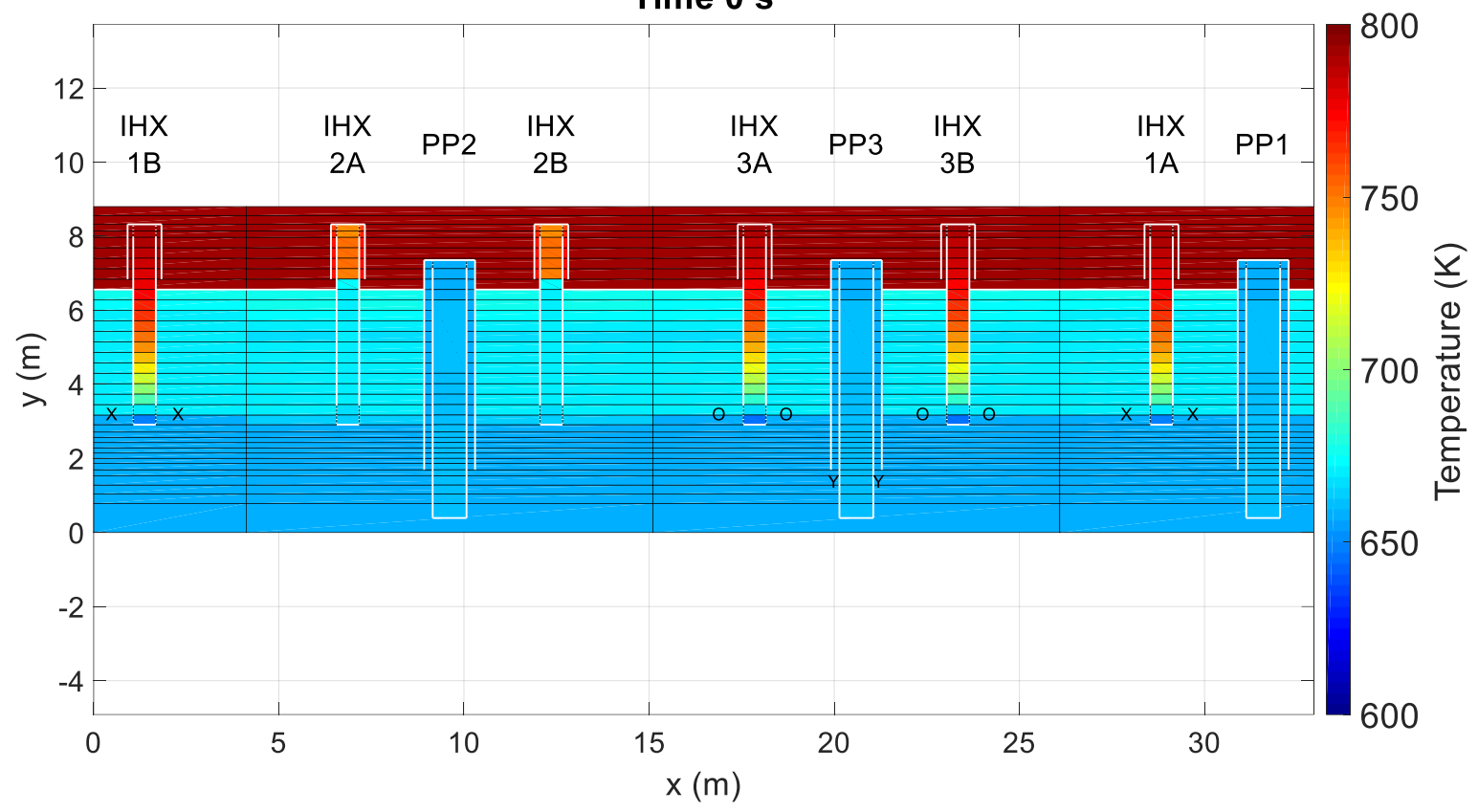

(a)

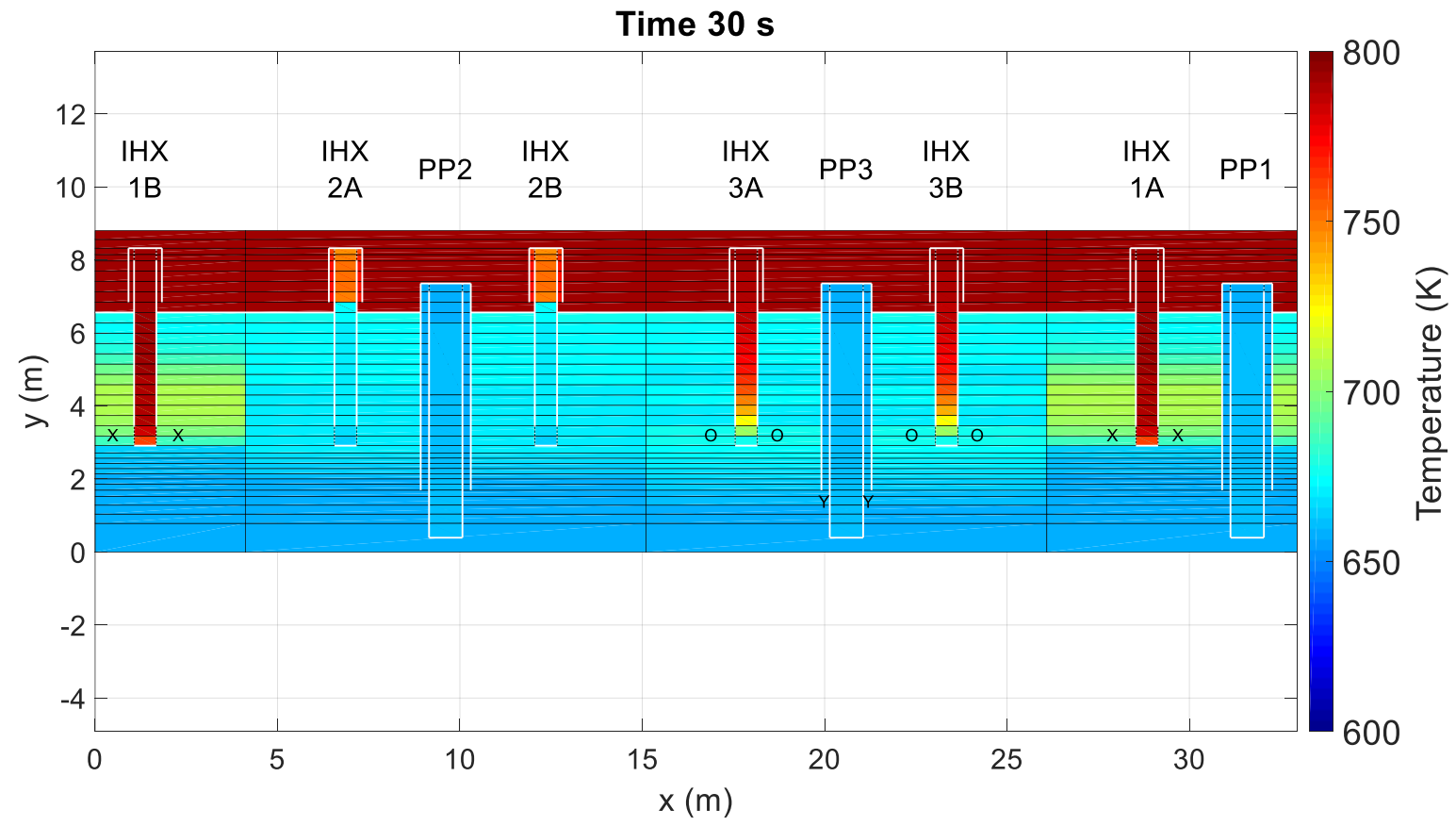

(b) 


\section{Time $60 \mathrm{~s}$}

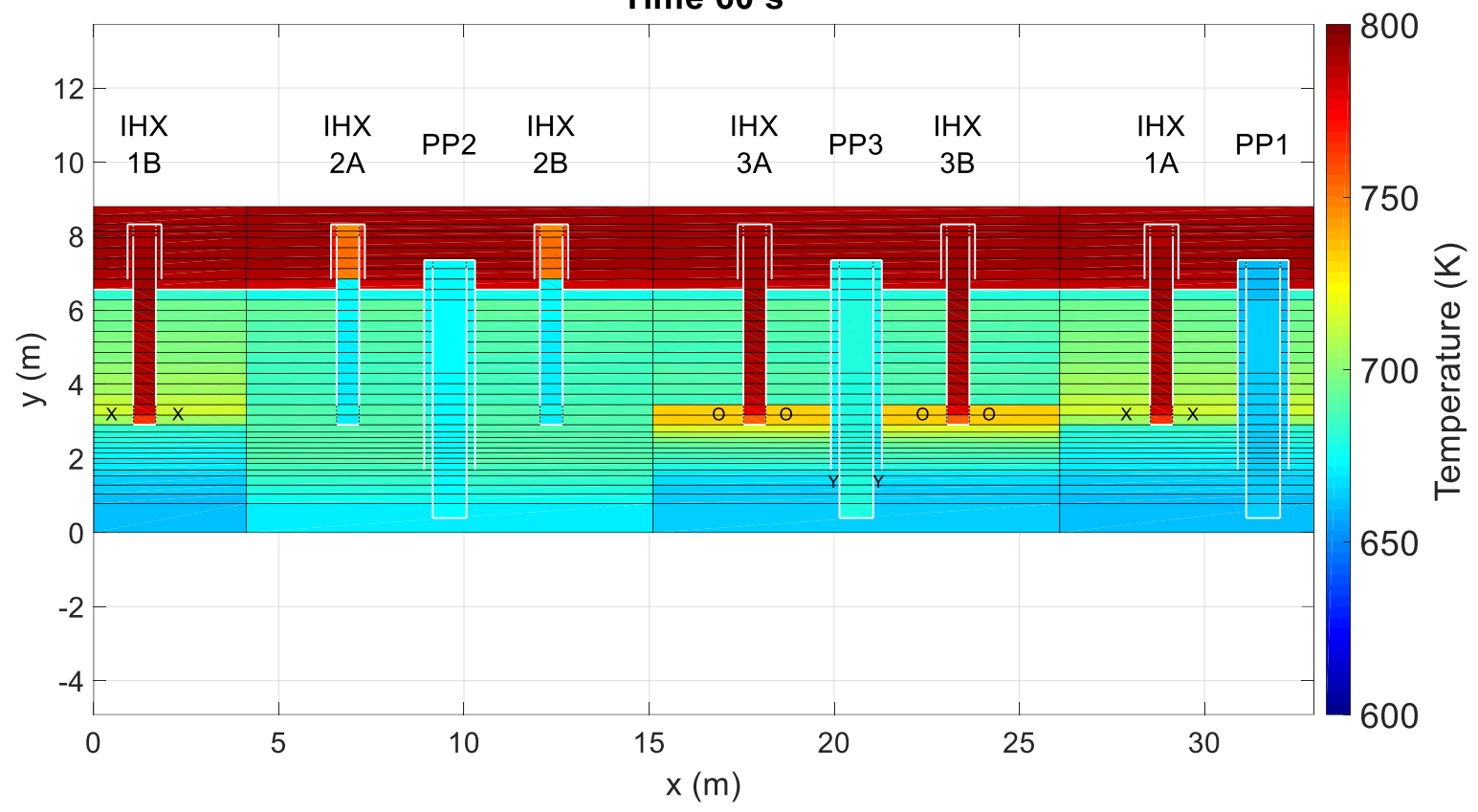

(c)

\section{Time $90 \mathrm{~s}$}

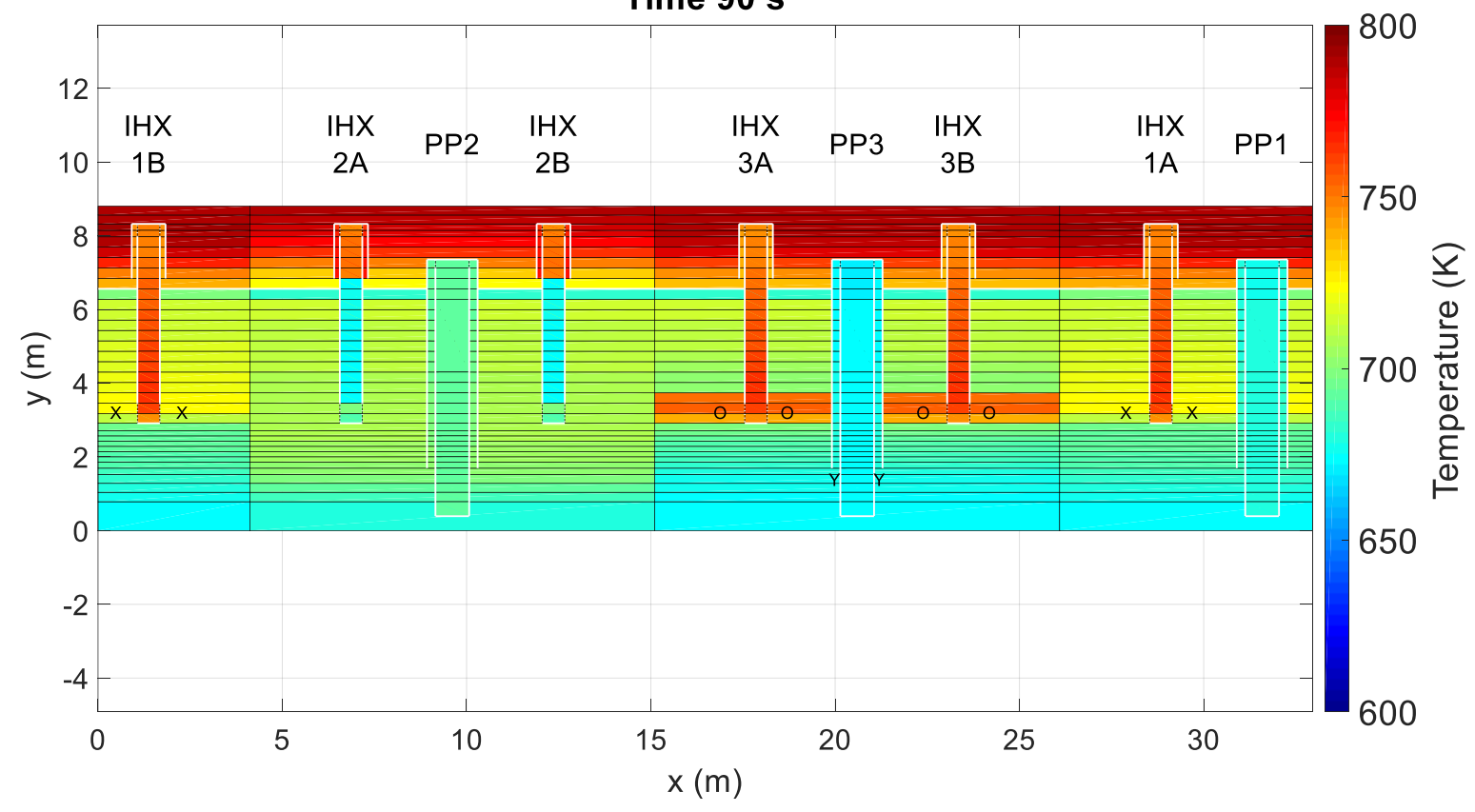

(d) 


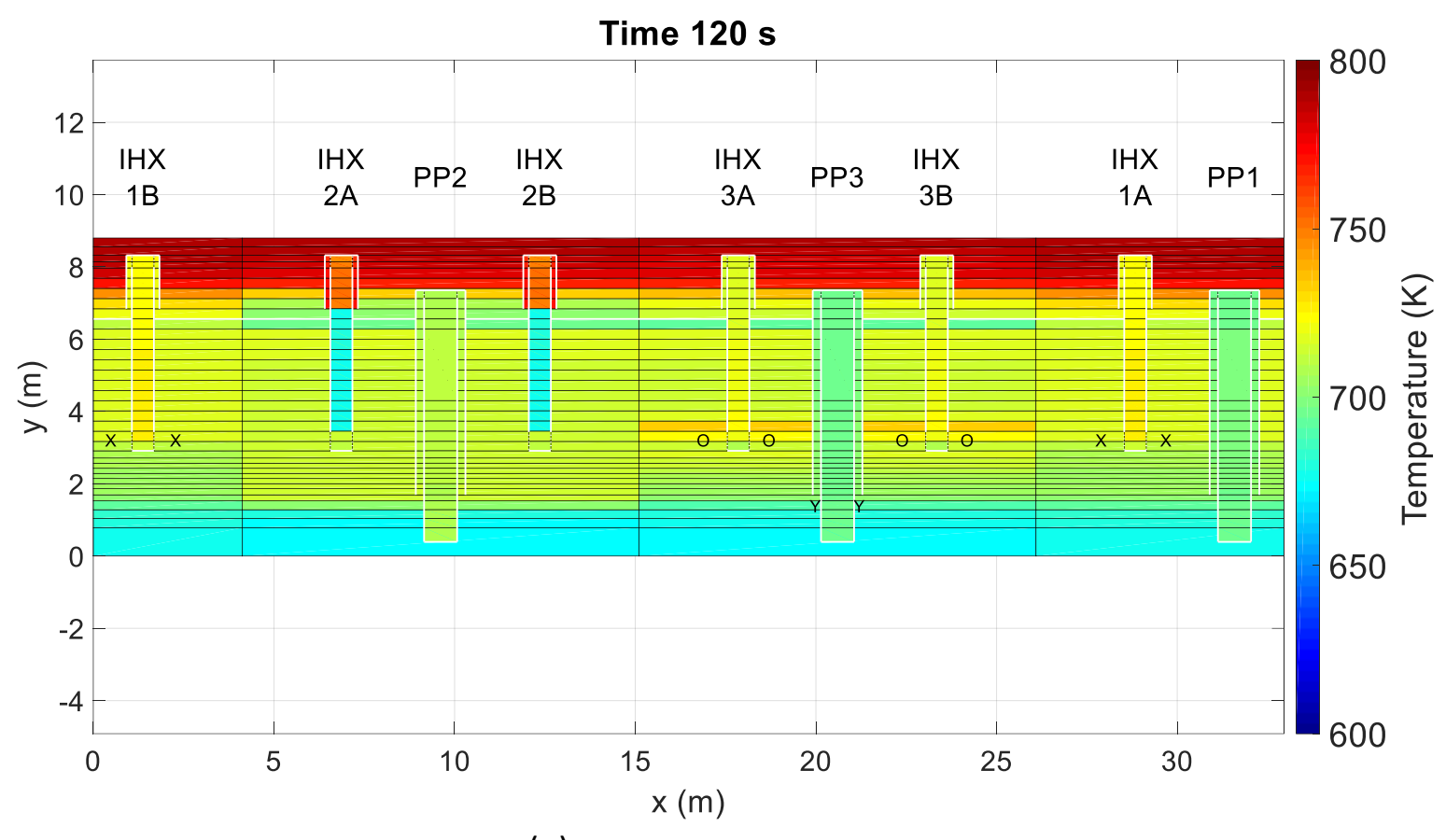

(e)

Fig. 8 Primary system temperature: 1D MODEL 


\section{Time $0 \mathrm{~s}$}

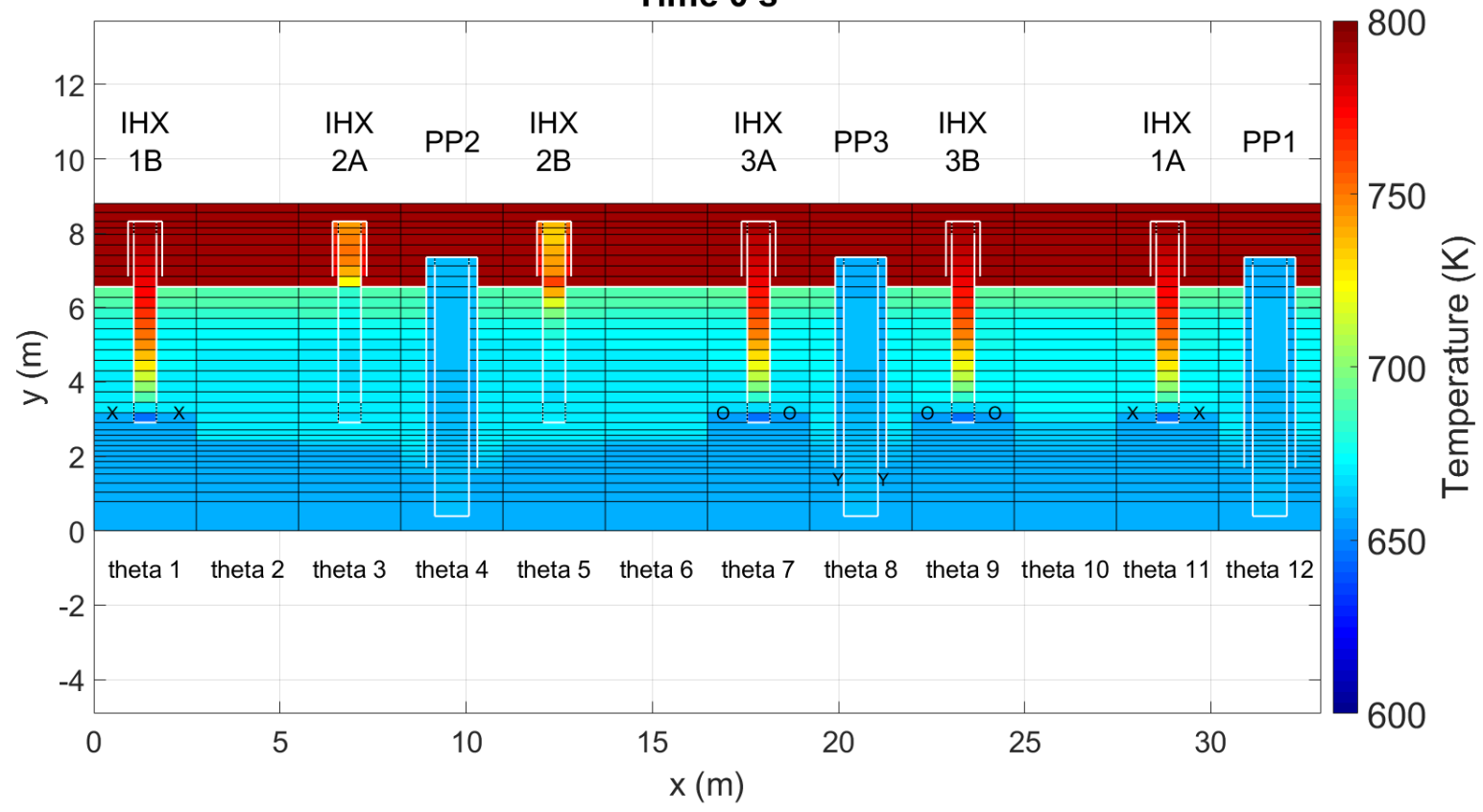

(a)

Time $30 \mathrm{~s}$

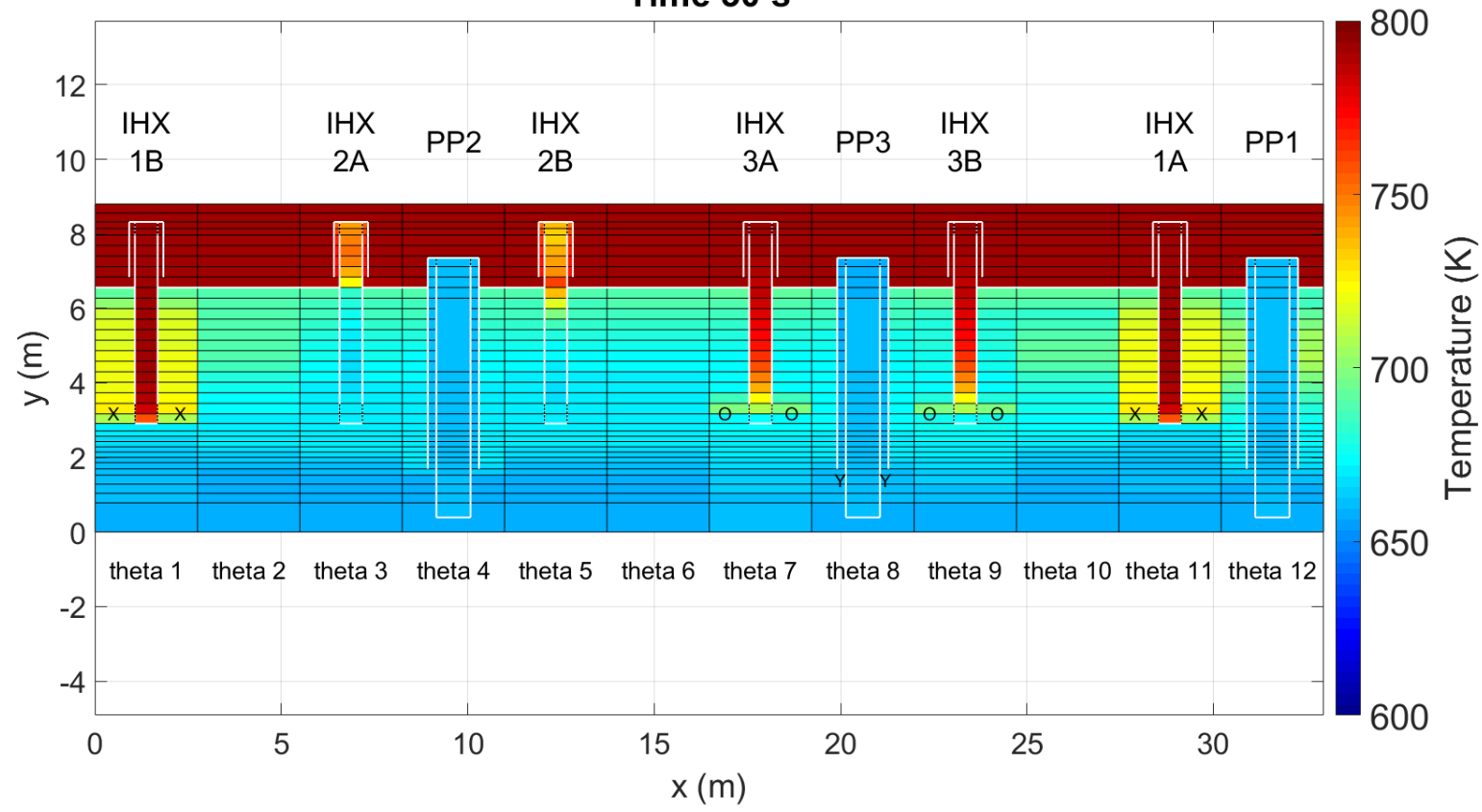

(b) 


\section{Time $60 \mathrm{~s}$}

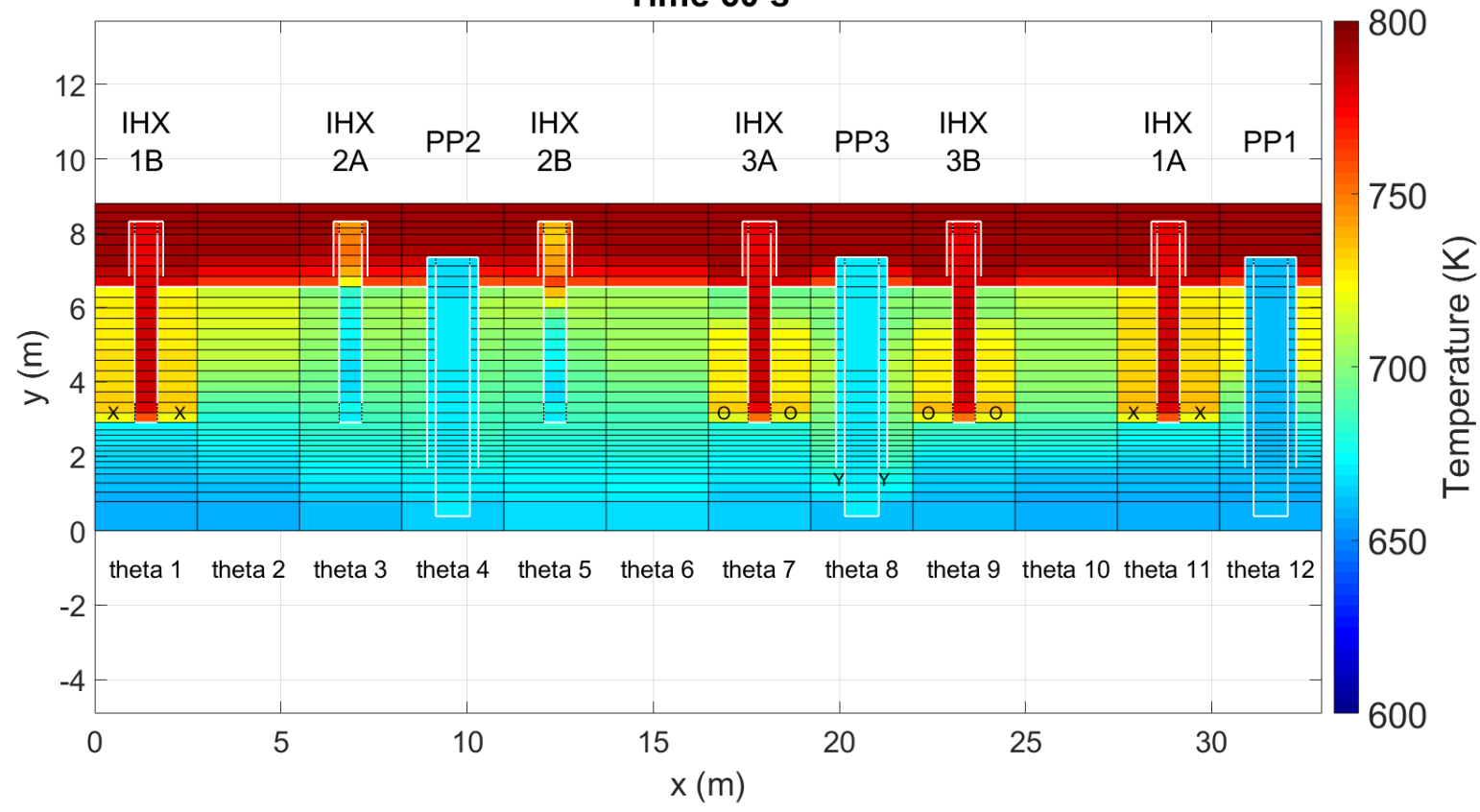

(c)

Time $90 \mathrm{~s}$

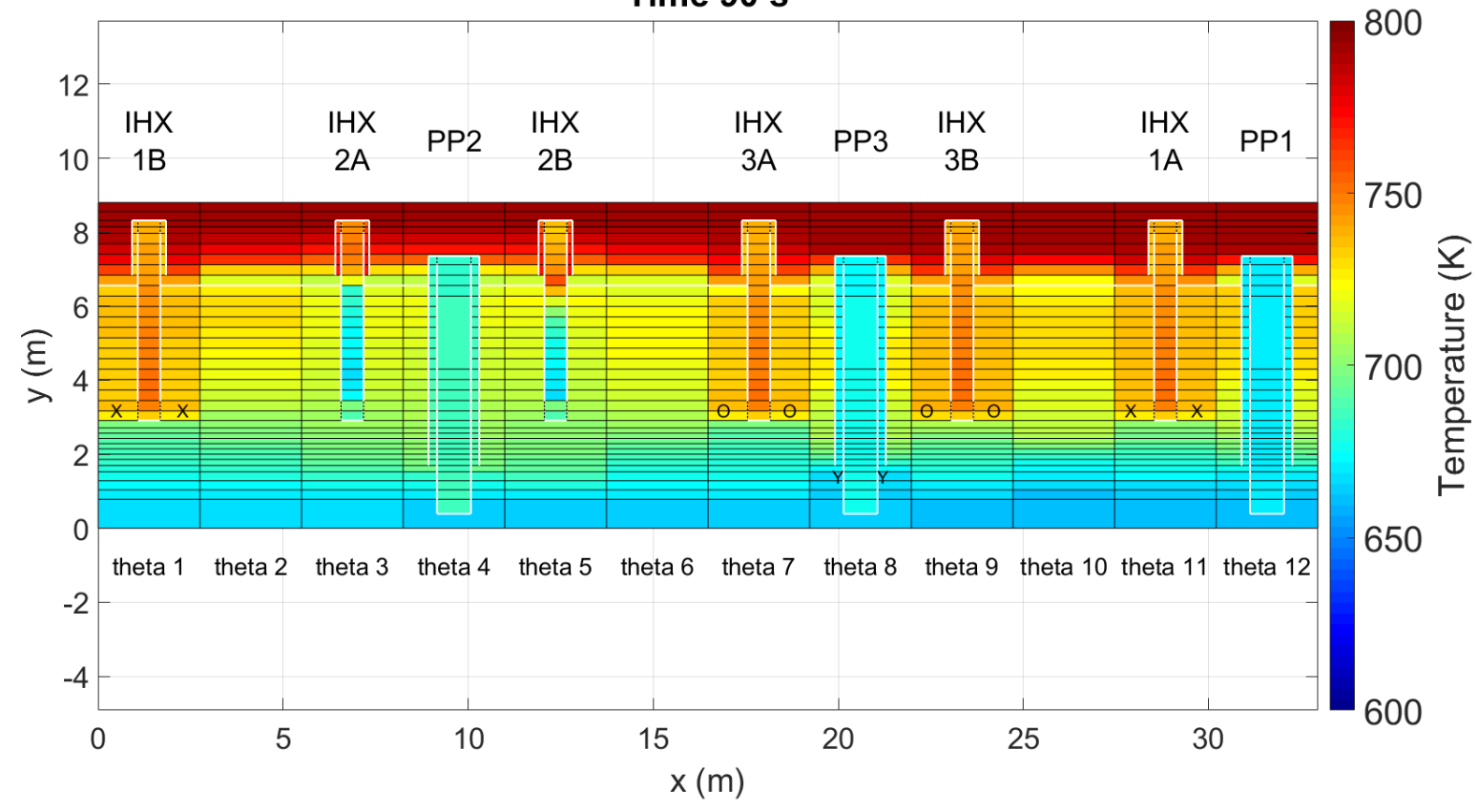

(d) 
Time $120 \mathrm{~s}$

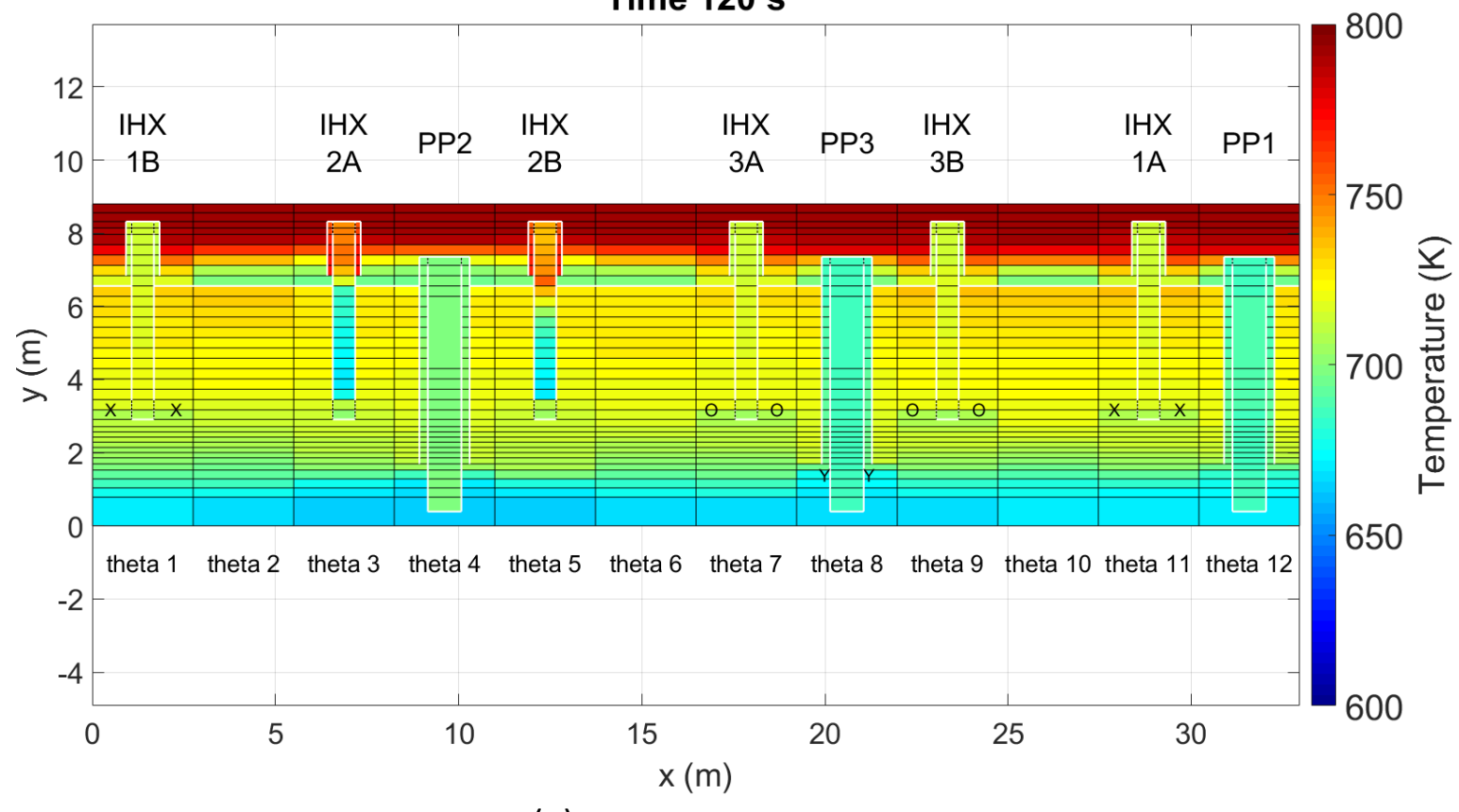

(e)

Fig. 9 Primary system temperature: 3D MODEL 


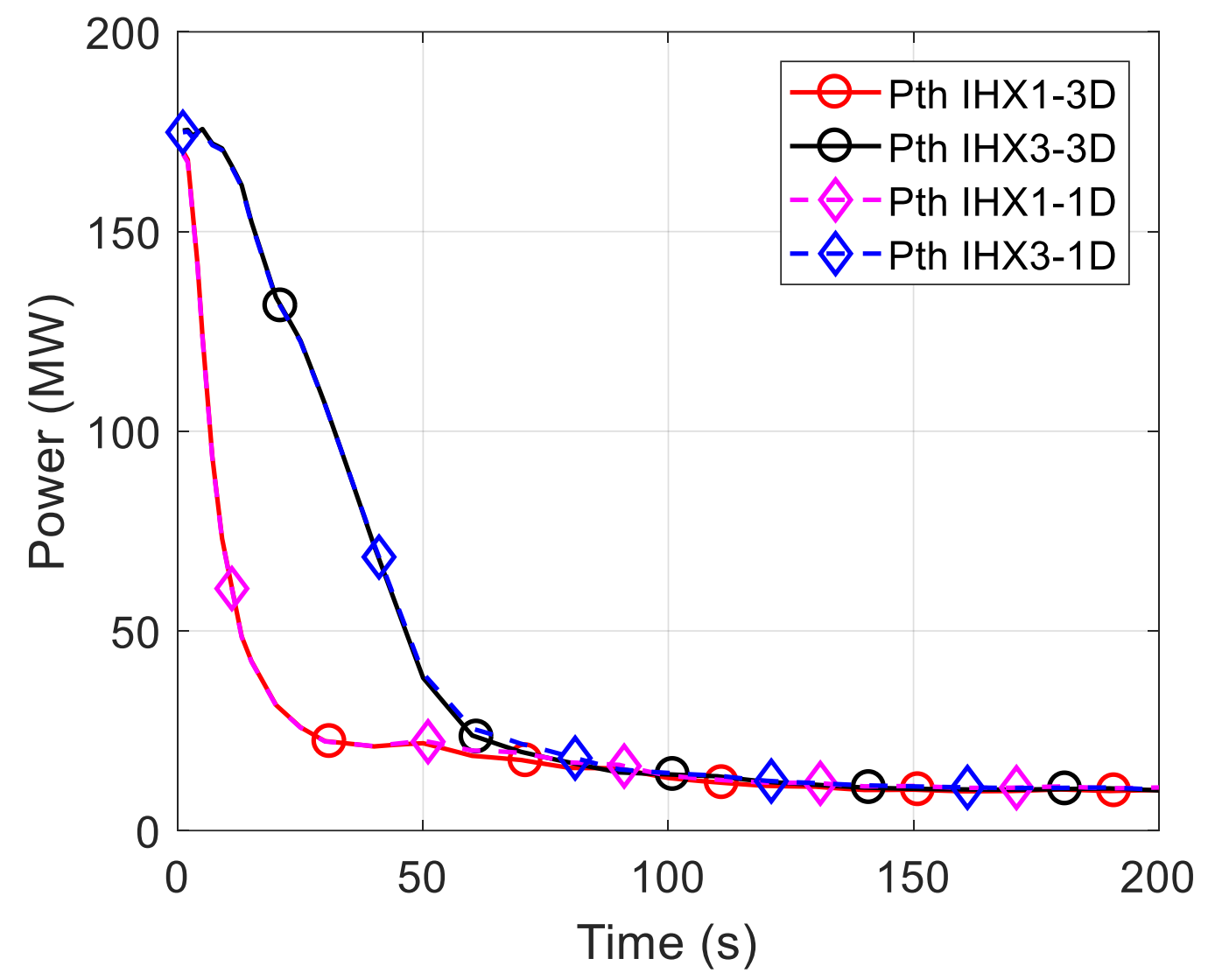

Fig. 10 Power removed by IHXs 


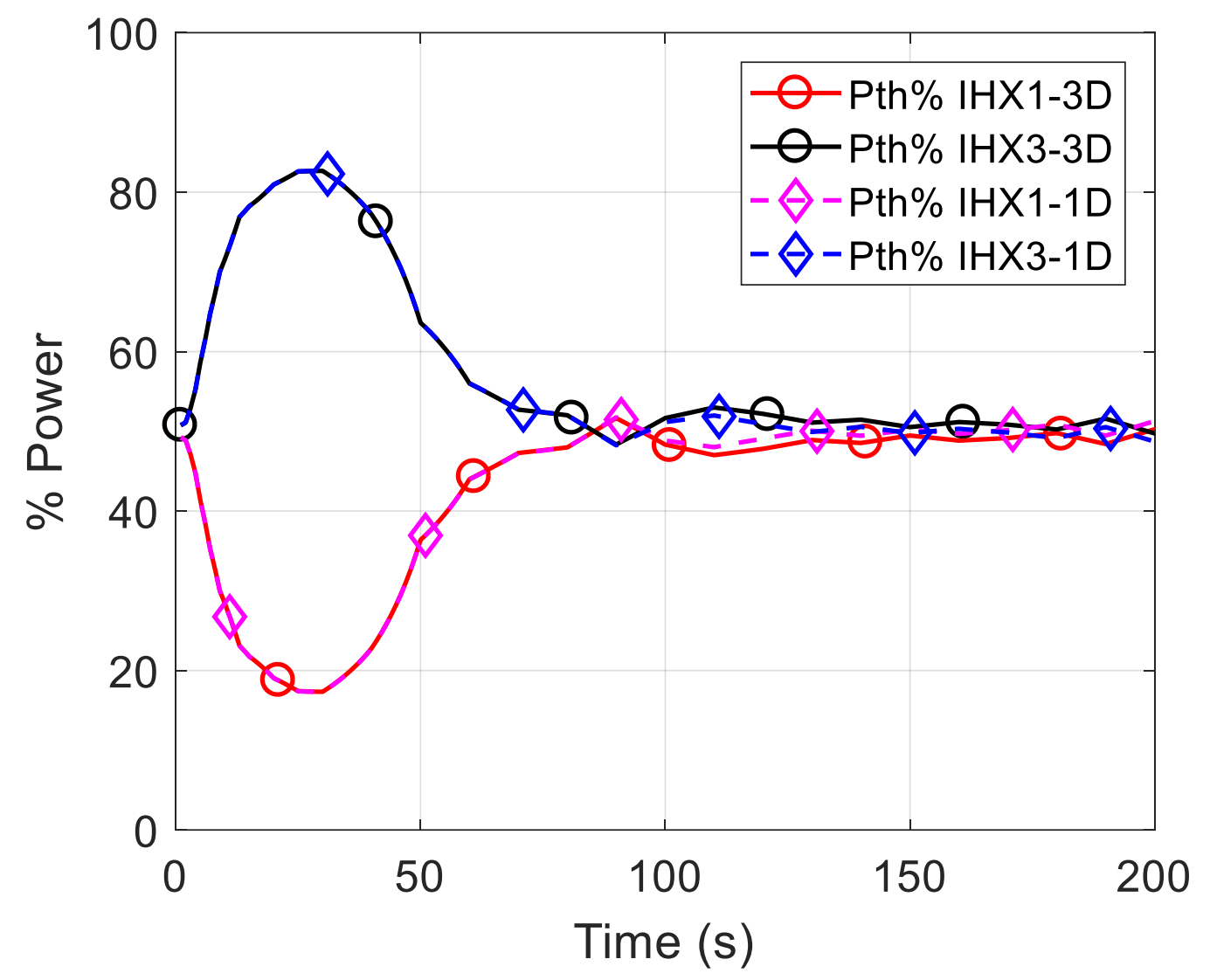

Fig. 11 Power \% removed by IHXs 


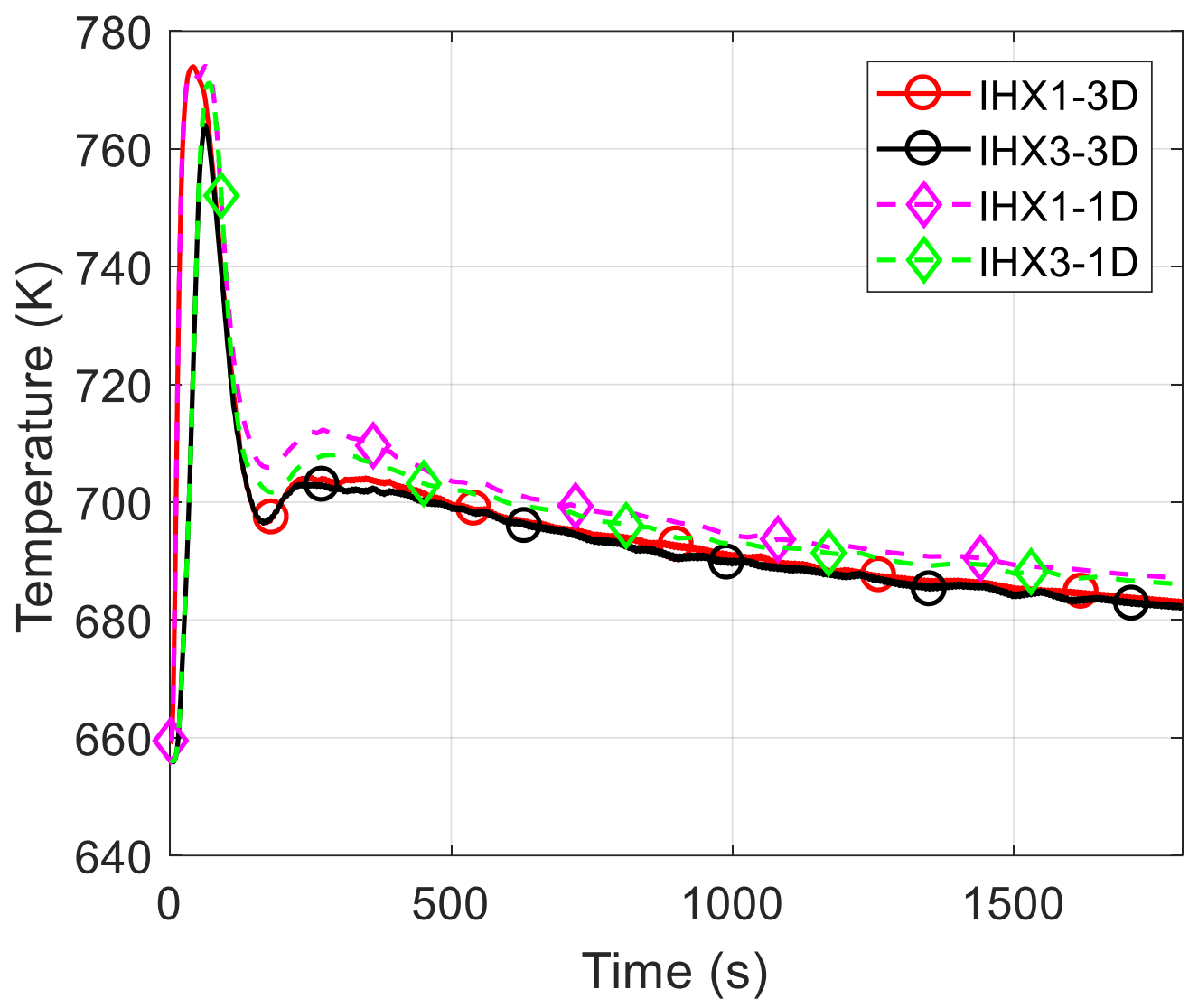

Fig. 12 IHXs outlet coolant temperature 


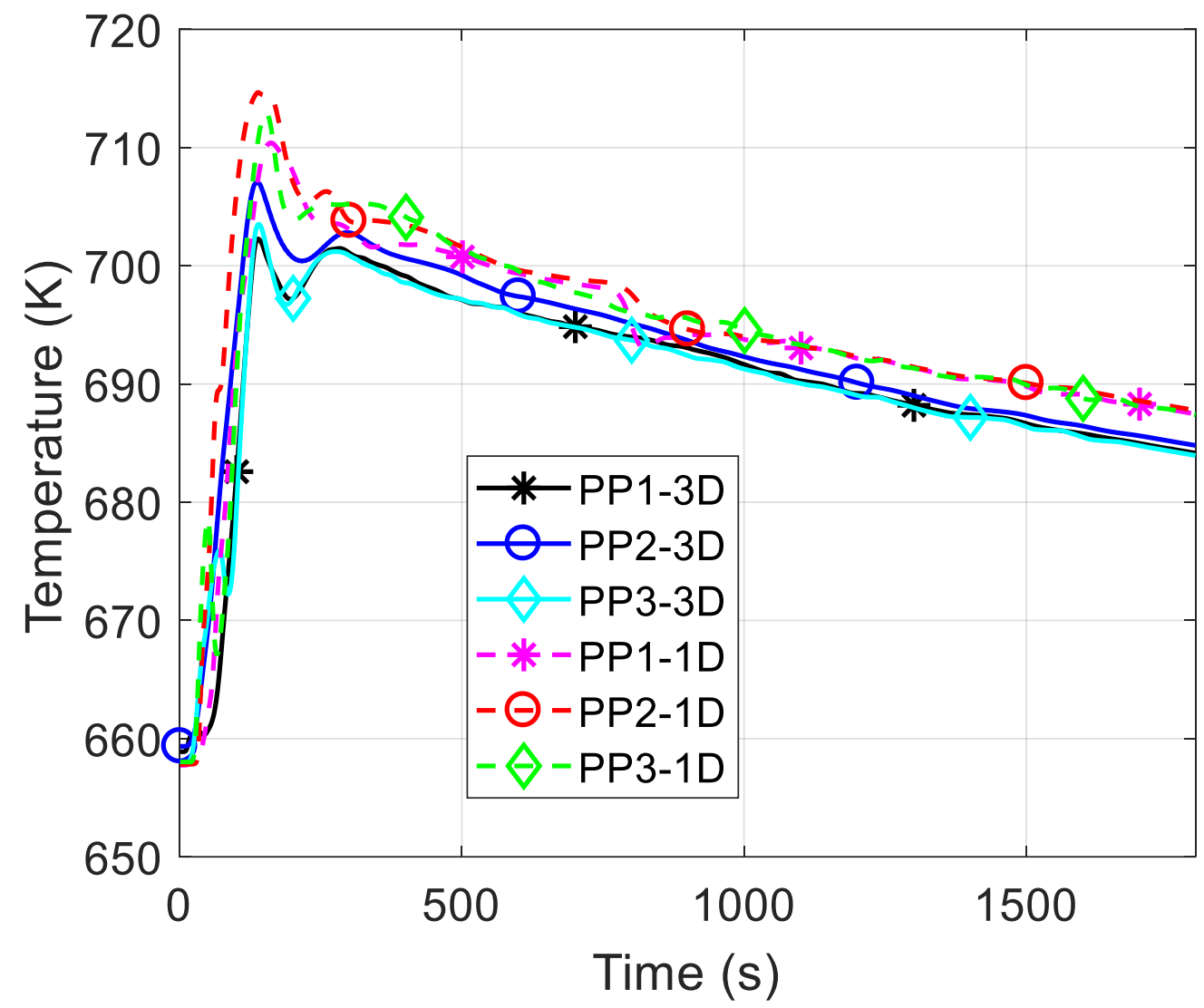

Fig. 13 PPs inlet coolant temperature 


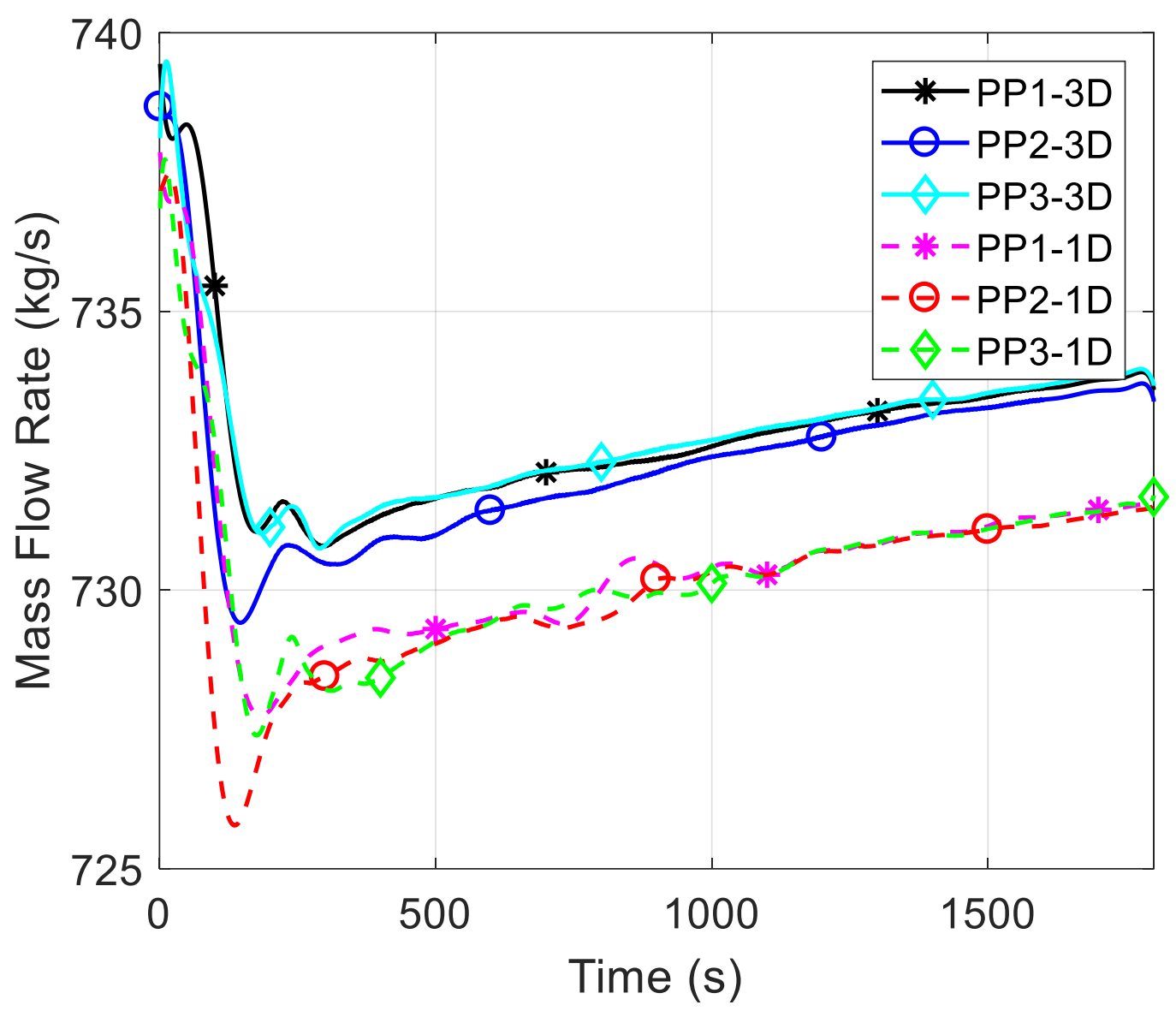

Fig. 14 PPs mass flow rate 


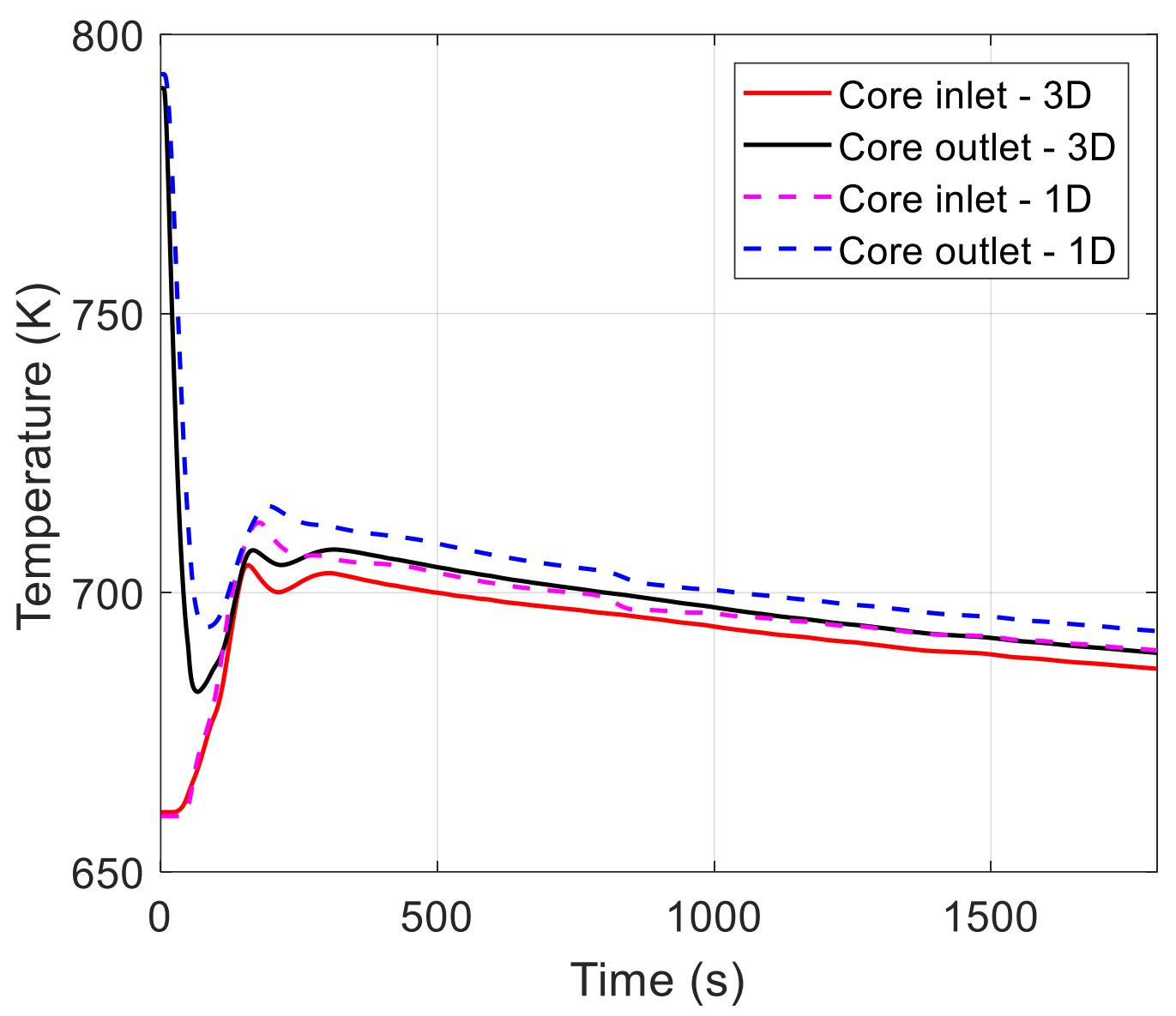

Fig. 15 Core inlet and outlet temperature 


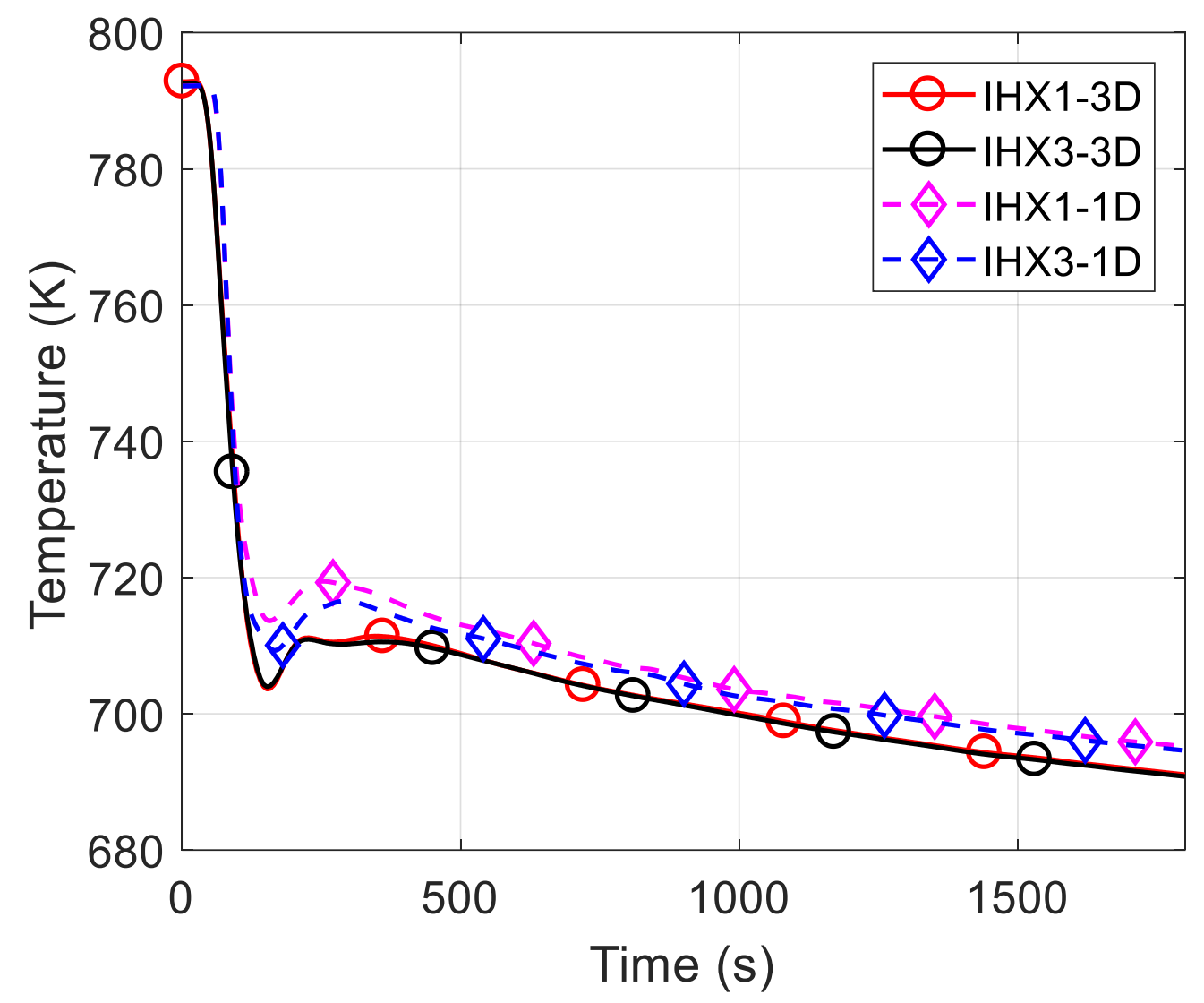

Fig. $16 \mathrm{IHXs}$ inlet coolant temperature 
Journal of Nuclear Engineering and Radiation Science, Vol. 6, No. 1, 011301. DOI: 10.1115/1.4044847

\begin{tabular}{|c|c|}
\hline Time (s) & Action \\
\hline 0 & $\begin{array}{c}\text { Secondary pump trip (on loop 1): speed reduced } \\
\text { from 700 to 100 rpm in about 13 s }\end{array}$ \\
\hline 5 & $\begin{array}{c}\text { Automatic shutdown: insertion of the control } \\
\text { rods (1.4 mm/s) for 45 s } \\
\text { Turbine trip }\end{array}$ \\
\hline 48 & $\begin{array}{c}\text { Secondary pump speed reduced (on loop 3) from } \\
700 \text { to 110 rpm in about 60 s }\end{array}$ \\
\hline 1800 & Scram \\
\hline
\end{tabular}

Table 1 Dissymmetrical test main events sequence 
Journal of Nuclear Engineering and Radiation Science, Vol. 6, No. 1, 011301. DOI: 10.1115/1.4044847

\begin{tabular}{|l|c|c|}
\hline \multicolumn{1}{|c|}{ QUANTITY } & Unit & Value \\
\hline Primary circuit balance & $\mathrm{MW}$ & 341 \\
\hline T secondary system IHX inlet & $\mathrm{K}$ & 594 \\
\hline T secondary system IHX outlet & $\mathrm{K}$ & 787 \\
\hline MF IHX-1A secondary system & $\mathrm{kg} / \mathrm{s}$ & 347 \\
\hline
\end{tabular}

Table 2 Nominal (full power operation) boundary conditions 
Journal of Nuclear Engineering and Radiation Science, Vol. 6, No. 1, 011301. DOI: 10.1115/1.4044847

\begin{tabular}{|l|c|c|c|}
\hline \multicolumn{1}{|c|}{ QUANTITY } & Unit & R5-3D - 1D model & $\begin{array}{c}\text { R5-3D - 3D } \\
\text { model }\end{array}$ \\
\hline T Core inlet & $\mathrm{K}$ & 660 & 661 \\
\hline T Core outlet & $\mathrm{K}$ & 793 & 791 \\
\hline T primary system IHX inlet & $\mathrm{K}$ & 792 & 660 \\
\hline T primary system IHX outlet & $\mathrm{K}$ & 660 & 2211 \\
\hline MF Total PP & $\mathrm{kg} / \mathrm{s}$ & 2211 & 219 \\
\hline MF Total core & $\mathrm{kg} / \mathrm{s}$ & 1992 & 498 \\
\hline MF VCS & $\mathrm{kg} / \mathrm{s}$ & 219 & 48 \\
\hline MF IHX-1A primary system & $\mathrm{kg} / \mathrm{s}$ & 198 & \\
\hline $\begin{array}{l}\text { Mean computational time } \\
\text { (CPU time / problem time) }\end{array}$ & & & \\
\hline
\end{tabular}

Table 3 Comparison of 1D and 3D models results and CPU times of the nominal steady state calculations 